\title{
Structural Brain Differences in Breast Cancer Patients Compared to Matched Controls Prior to Chemotherapy
}

\author{
Carole Scherling (Corresponding author) \\ University of Ottawa, School of Psychology \\ 136 Jean Jacques Lussier, Vanier Hall, room 2068, Ottawa, ON, K1N6N5 Canada \\ E-mail: csche087@uottawa.ca; cscherling@memory.ucsf.edu \\ Barbara Collins \\ Ottawa Hospital and University of Ottawa \\ 1053 Carling Avenue, Civic Campus, room A603, Ottawa, ON, K1Y4E9, Canada \\ Joyce MacKenzie \\ Ottawa Hospital, 1053 Carling Avenue, Civic Campus, Ottawa, ON, K1Y4E9, Canada \\ Chris Lepage, Catherine Bielajew \& Andra Smith \\ University of Ottawa, School of Psychology \\ 136 Jean Jacques Lussier, Vanier Hall, Ottawa, ON, K1N6N5, Canada
}

$\begin{array}{ll}\text { Received: November 18, } 2011 & \text { Accepted: December 1, } 2011 \quad \text { Published: April 1, } 2012 \\ \text { doi:10.5539/ijb.v4n2p3 } & \text { URL: http://dx.doi.org/10.5539/ijb.v4n2p3 }\end{array}$

The Canadian Breast Cancer Foundation has funded this project.

\begin{abstract}
Understanding the relationship between chemotherapy and cognitive impairment requires information on pre-treatment variability between cancer patients and well-matched controls. The purpose of this study was to investigate neuroanatomical differences between breast cancer $(\mathrm{BC})$ patients and controls, prior to chemotherapy,controllingfor possible confounding variables. Twenty-three female early-stage BC patients underwent MRI scanning after surgery but before chemotherapy and were sex-, age- and education-matched to non-cancer controls. Whole brain and region of interest (ROI) group comparisons of grey (GM) and white matter (WM) were performed using voxel-based morphometry.Significant ROI structural differences between BC patients and controls were found depending on the type of analysis used and the covariates entered. This is one of the first imaging studies to focus on pre-chemotherapy neuroanatomical differences between BC patients and well-matched controls, considering demographic, psychological and biological factors in the analyses. Results highlight the importance of better understanding the whole patient prior to chemotherapy, stressing the importance of rigorous methodological procedures.
\end{abstract}

Keywords: Cognitive impairment, Magnetic resonance imaging (MRI), Voxel-based morphometry (VBM), Pre-treatment effects, Chemotherapy, Surgery, Neuropsychology, Anatomy

\section{Introduction}

Recent medical advances have greatly improved the odds of achieving long term survival in cancer patients. This has led to increased attention for improving post-treatment quality of life. One factor of particular interest is related to patient self-reports of cognitive impairments following chemotherapy treatment, most often revealed in breast cancer (BC) populations. Patients have coined terms like "chemo fog" and "chemo brain" to refer to these changes that can manifest both during and after treatment. The incidence of chemotherapy-related impairments is 
highly variable with a range of $17-75 \%$ reported across neuropsychological studies (Correa \& Ahles, 1997). Despite this variability, these assessments, along with both structural and functional neuroimaging investigations, support the existence of the self-reported deficits (Abraham et al., 2008; Ahles et al., 2002; Ahles, Tope, Furstenberg, Hann, \& Mills, 1996; Bender et al., 2006; Berglund, Bolund, Fornander, Rutqvist, \& Sjoden,1991; Brezden, Phillips, Bunston, \& Tannock, 2000; Brown et al., 1998;Castellon et al., 2004; Deprezet al., 2003; de Ruiter et al., 2010; Ferguson, McDonald, Saykin, \& Ahles, 2007; Gottschalk, Holcombe, Jackson, \& Bechtel, 2003; Hurria et al., 2006; Inagaki et al., 2007; Jenkins et al., 2006; Kesler et al., 2009; Kreukels et al., 2005; Kreukels et al., 2006; Kreukels et al., 2008; Mar Fan et al., 2005; McDonald, Conroy, Ahles, West, \& Saykin, 2010; Saykin et al., 2006; Saykin, Ahles, \& Schoenfeld, 2003; Schagen et al., 1999; Scherwath et al., 2006; Servaes, Verhagen, \& Bleijenberg,2002;Shilling, Jenkins, Morris, Deutsch, \& Bloomfield, 2005; Silverman et al., 2007; Stewart et al., 2007; Tchen et al., 2003; van Dam et al, 1998; Wagner et al., 2006; Wieneke \& Dienst, 1995; Wefel, Lenzi, Theriault, Davis, \& Meyers, 2004), particularly in domains such as working memory, executive function, and processing speed. Previous research has investigated neuroanatomical changes occurring in the chemotherapy-treated brain, which could possibly be related to the reported functional cognitive changes. However, these studies have mostly focused on post-treatment structural changes, without investigations of potential pre-treatment differences between cancer patients and controls.

Post-treatment imaging studies have revealed structural differences between chemotherapy-treated patients and controls. In particular, antineoplastic agents (widely used in chemotherapy) are able to pass through the blood brain barrier, penetrate the brain and affect its structure. Previous research has found higher than expected concentrations of such agents in brain tissue and cerebrospinal fluid (CSF) of treated patients (Troy et al., 2004; Tuxen\& Werner, 1994). White matter (WM) is particularly vulnerable to such neurotoxins and use of MRI techniques has increased recognition of WM changes related to drug intake.

The first study to consider post-chemotherapy structural changes investigated WM volumes in eight advanced stage BC patients receiving high-dose regimens (Brown et al., 1998). No baseline abnormalities were revealed, yet three out of the four remaining patients in the study showed a progressive increase in abnormal WM volume at three months post-chemotherapy. These volume changes stabilized from 6 to 12 months after chemotherapy completion. These treatment-related WM changes after chemotherapy were not accompanied by persistent neurologic symptoms.

WM volume fluctuations are strongly correlated with grey matter (GM) alterations. Voxel-based morphometry (VBM) techniques were applied to investigate whole brain changes in chemotherapy-treated cancer survivors at 5 years post-treatment (Saykin et al., 2003). Chemotherapy-treated patients revealed diffuse cortical and subcortical WM volume reductions as well as local bilateral volume reduction of neocortical GM compared to healthy controls.

Another VBM study (Inagaki et al., 2007) investigated adjuvant chemotherapy-treated BC survivors andsurgery-only/local-therapy only BC survivors. Scanning took place at year one (range: 3-15 months) and year three (range: 27-39 months) post-treatment. At the year one, chemotherapy patients showed GM losses in the right prefrontal cortex and para-hippocampal gyrus and WM decreases in bilateral middle frontal gyri, left para-hippocampal gyrus, left precuneus and right cingulate gyrus. A positive correlation between volume loss and performance on tests of attention and memory was also revealed. These results were no longer evident at the three-year post-treatment scan.

A first prospective VBM investigation attempted to control for the effects of cancer itself (McDonald et al., 2005). Chemotherapy-treated BC patients, non-chemotherapy treated BC patients and healthy controls were scanned at baseline, one month after chemotherapy and one year later. Whole brain GM assessments revealed no baseline group differences, yet a post-treatment decline in both cancer groups compared to controls was revealed. Chemotherapy patients revealed GM reductions in bilateral middle frontal gyri and left cerebellum, while non-chemotherapy patients had decreases in right cerebellum. Also, chemotherapy patients revealed post-treatment decreases in bilateral frontal, temporal and cerebellar regions as well as right thalamus. Meanwhile at one year compared to one month post-treatment, the same patients showed recovery in bilateral superior frontal, left middle frontal, right superior temporal and cerebellar regions, but persistent decreases in right thalamus, medial temporal lobe, left middle frontal gyrus, right precentralgyrus, medial frontal, superior frontal gyri and bilaterally in other cerebellar regions.

Abraham et al. (2008) applied a fractional anisotropy (FA) technique to investigate WM integrity of the corpus callosum in chemotherapy-treated $\mathrm{BC}$ patients withself-reports cognitive deficits. Additionally, each participant completed a digit symbol test that showed slower processing speed in patients compared to controls. Also, 
treatment correlated with lower FA scores in the genu and lower FA scores correlated with cognitive deficits reported by patients.

A more recent diffusion study used FA and mean diffusivity (MD) techniques to examine cerebral WM integrity in post-chemotherapy BC patients, non-chemotherapy BC patients and healthy controls (Deprez et al., 2010). Chemotherapy patients showed decreased FA in both frontal and temporal tracts and increased MD in frontal WM compared to both non-chemotherapy patients and controls. FA scores in the temporal and parietal tracts correlated with neuropsychological tests (attention and processing speed) while self-reports of cognitive failure negatively correlated with frontal and parietal WM. Overall, chemotherapy patients performed worse on neuropsychological tests in contrast to the other groups, with 7 out of 17 classified as clinically impaired. These "impaired" patients had even lower FA values than their "unimpaired" chemotherapy counterparts and controls.

Use of the term chemo fog as well as the current research focus on post-treatment effects, leads to an assumption that chemotherapy is the sole causative agent of these cognitive impairments. However, one fMRI study examined pre-treatment data and revealed cognitive and neural differences in $\mathrm{BC}$ patients compared to healthy controls (Cimprich et al., 2010). Patients were less accurate and slower than controls in the high-demand task conditions, additionally showing larger activations in the right inferior frontal gyrus and bilaterally in the attention/working memory circuitry. This study highlights the importance of baseline assessments since, without an appropriate baseline investigation, the effects of the disease itself or associated confounds could be misattributed to an effect of treatment. Several confounding variables may manifest at baseline, and these are now beginning to be considered.

First, some studies have attempted to control for the presence of cancer by including a matched cancer group that had not been treated with a chemotherapy regimen (de Ruiter et al., 2010; McDonald et al., 2010; Saykin et al., 2006). Ongoing studies have reported elevated levels of multiple cytokines in cancer patients, with values being highest post-surgery and persisting for 6-60 months after diagnosis (Vardy et al., 2007). An overproduction or inappropriate production of cytokines can result in disease, inflammation and/or tissue destruction. For example, cytokine activity in the hippocampus has been linked to a disruption in memory consolidation (Maier \& Watkins, 2003). Yet, side-effects of a differing treatment received by non-chemotherapy patients becomes a confound itself, with treatments such as radiation or anti-estrogen regimenswhich may contribute to fatigue (Noal et al., 2010)and have been linked with cognitive dysfunction (Castellon et al., 2004).

Second, previous literature has suggested a cognitive decline after general anesthesia, but predominantly in an elderly population $(60+)$ who are more inclined to develop long term deficits (Dijkstra, Houx, \& Jolles, 1999; Dodds \& Allison, 1998; Monk et al., 2008). Therefore, anesthesia administration has cognitive effects that could be misattributed to future chemo fog deficits. Possible negative effects of surgery in BC patients have only been considered in one imaging study (McDonald et al., 2010) as a covariate which modified the statistical model, did not change the overall results. However, this study compared two BC groups who had both undergone surgery, thereby both possibly showing the same profile of elevated cytokine levels and cognitive deficits related to general anesthesia.

Third, stressis routinely measured in chemo fogstudies through self-reportand correlates highly with complaints of cognitive disturbances (Bender et al., 2006; Castellon et al., 2006; Jenkins et al., 2006; Schagen et al., 1999; Schagen et al., 2002; Shilling \& Jenkins, 2007; Shilling et al., 2005; van Dam et al., 1998). Cortisol is the stress hormone in humans and elevated levels are related to increased activity of the hypothalamic-pituitary-adrenal (HPA) axis and/or administration of therapeutic glucocorticoids (part of immunosuppressive therapy used in cancer treatment). Elevated cortisol levels have been shown to affect brain anatomy (Bremner, Southwick, \& Charney 1999; McEwen \& Magarinos, 1997; Sapolsky, 1985) as well as memory functions (Lupien, Gillin, \& Hauger, 1999). One particularly vulnerable region in the brain is the hippocampus, with smaller volumes seen in populations with higher stress reactivity (McEwen, 1999; Pruessner et al., 2005; Starkman, Gebarski, Berent, \& Schteingart., 1992) and transiently in chemotherapy-treated BC survivors (Inagaki et al., 2007). Cortisol may indirectly play a role in the development of post-chemotherapy cognitive deficits since elevated levels during stress (ex: a cancer diagnosis and/or treatment) have been shown to augment capillary permeability of the blood brain barrier (Tuxen \& Werner, 1994). This increased permeability means that cortisol could potentially exacerbate the adverse effects of chemotherapy agents in the brain.

Finally, a typically older and post-menopausal BC population requires measuring baseline estrogen levels. Estrogen has been suggested to have neuroprotective qualities, thereby helping maintain cognitive capacities, but the exact mechanisms by which it exerts such protection remains unclear. Previous research has suggested an interaction between various neurotransmitter systems, neurotrophic factors, as well as nuclear estrogen receptors. 
The latter are particularly present in areas such as the amygdala and hippocampus, both involved in memory and learning (Behl, 2002; McEwen, 2002; Shughrue\&Merchenthaler, 2000). Post-menopausal studies have indicated that women report declining cognitive capacities and show decreased bilateral hippocampal volumes, an effect minimized by estrogen therapy(Lord, Buss, Lupien,\&Pruessner, 2008).

Overall, there are few neuroimaging investigations of cancer patients prior to commencement of chemotherapy-treatment. Results from existing research are conflicting and thus, further pre-chemotherapy research is required. The current paper investigated baseline neuroanatomical differences in new BC patients (prior to chemotherapy) compared to individually-matched healthy controls. Suggested baseline confounds associated with cancer populations were considered as covariates, including: days since surgery, diurnal cortisol levels, estrogen, depression and anxiety inventories, and IQ. It was hypothesized that there would be both grey and white matter volumetric differences between patients and controls at baseline. It was also hypothesized that consideration of suspected confound variables may modify the analyses with no covariates,as seen in previous studies (McDonald et al., 2010), revealing additional volumetric group differences and/or expose the highly heterogeneous nature of the patient population. Volumes were assessed by whole brain analyses and by ROI investigation of brain areas reported in the post-chemotherapy literature.

\section{Methods}

Twenty-three newly diagnosed breast cancer (BC) women were recruited through the Ottawa Hospital Regional Cancer Centre (average age: $51 \pm 8.5$ years, range: $35-64$ ). At the time of the MRI scan, patients had undergone mastectomy or lumpectomy for early stage $\mathrm{BC}$ and were scheduled to commence a chemotherapy regimen. The majority of $\mathrm{BC}$ patients received $\mathrm{FEC} / \mathrm{T}$ combination treatment (fluoraouracil, epirubicin, cyclophosphamide, taxotere) with a few receiving either TC (Taxotere, clyclophophamide) or AC (Adriamycin, cyclophosphamide).Inclusion criteria were: female, no previous cancer or cancer treatment, no unstable psychiatric/ neurological illness, no history of substance abuse, Beck Depression Inventory (BDI-II;Beck, Steer,\& Brown, 1996) scores of $<20$ and $<15$ for the Beck Anxiety Inventory (BAI;Beck\& Steer, 1990), fluency in English, and minimum grade 8 education. MRI exclusion criteria included left-handedness, sight problems, claustrophobia, pacemaker, and metal implants. Healthy controls (average age: $50 \pm 9$ years, range: 30-62) were recruited by a combination of patient nominations and through posters/website ads. Each non-cancer control was sex-, age- and education-matched to each individual cancer patient and also met the above inclusion and exclusion criteria. Controls followed the same procedure as their index $\mathrm{BC}$ patient.

\subsection{Neuropsychological assessments}

All participants completed baseline psychometric tests as well as an MRI scanning session. The $2 \frac{1}{2}$ hour baseline psychometric battery was comprised of: social / medical history, classic pencil-and-paper tests, and a 30 minute computerized cognitive test (CNS Vital Signs; https://www.cnsvs.com/). This computerized test battery has been validated in a broad age range and across clinical and non-clinical populations (including cancer patients), as well as proven sensitive in monitoring patient's cognitive status over time (Gualtieri\& Johnson, 2006). In particular, it measures: attention, reaction time, working memory, executive function as well as visual and verbal episodic memory. Raw neuropsychological data were converted to standardized scores based on the means and standard deviations of the matched healthy control group. Summary scores for several cognitive domains were computed as well as an overall cognitive summary calculated by averaging all of the cognitive scores. Cognitive domains were computed based on both rational and empirical grounds. Nineteen tests comprised the neuropsychological battery from which 6 cognitive domains were extracted: 1 . Verbal Memory (Hopkins Verbal Learning Test-Revised (HVLT-R; Brandt \& Benedict, 2001) and CNSVS Verbal Memory), 2. Processing Speed (WAIS-III (Wechsler, 1997) Digit-symbol coding, WAIS-III Symbol Search, controlled oral word association (Benton, Hamsher, \& Sivan, 1994), CNSVS Processing speed, CNSVS Executive Functioning, CNSVS Reaction time and CNSVS Cognitive Flexibility), 3. Attention (WAIS-III Digit Span, WAIS-III Letter-number sequencing, Paced Auditory Serial Attention Test (PASAT; Gronwall, 1997), CNSVS Sustained attention and Trailmaking Test, Part B; Army Individual Test Battery, 1944), 4. Visual Memory (CNSVS Visual Memory, Brief Visuospatial Memory Test (BVMT; BVMT-R; 67) and CNSVS Working Memory), 5.Reasoning (CNSVS Reasoning) and 6.Verbal Short-term Memory (Auditory Consonant Trigrams;Boone, Miller, Lesser,\&D'Elia, 1990).Additionally, each participant completed the Rosenberg Self-esteem questionnaire (RSE: Rosenberg, 1985) and the Questionnaire for Competence and Control (FKK; Krampen, 1991) at the scanning session. 
Demographic, clinical neuropsychological and self-esteem data were analyzed by two-tailed independent t-tests using Statistical Package for the Social Sciences version 18.0 program (SPSS v. 18.0, Chicago, IL). Correlational analyses were also conducted to reveal any existing relationship between factors.

\subsection{Assessment of biological markers}

Patient hospital record reviews provided baseline blood work (hemoglobin, white blood cell, neutrophil). Salivary samples were collected to assess free cortisol levels, a valid biological marker of the free fraction of the major human stress hormone (Kirschbaum \& Hellhammer, 1994). At-home sampling kits were given to individual participants, each containing 14 cotton salivettes for cortisol sampling and detailed instructions. Participants were asked to follow a rigid sampling schedule for two typical and consecutive weekdays. Cortisol was sampled each of the two days at: Awakening, 30 min after awakening, 1 hour after awakening (participants could consume food and drink after this sample), 10am, $2 \mathrm{pm}, 6 \mathrm{pm}$ and $9 \mathrm{pm}$. This schedule provided a circadian cortisol profile for each participant. This is an important component since circadian cortisol rhythms are affected in high stress and in clinical populations (Backhaus, Junghanns, \& Hohagen, 2004; MacHale et al., 1998; Monteleone \& Maj, 2009; Pruessner et al., 1997; Pruessner, Hellhammer, \& Kirschbaum, 1999). The completed samples were preserved in a freezer until the next appointment. The saliva samples were analyzed for cortisol using ELISA techniques described by Salimetrics (at salimetrics.com). Intra- and inter-assay variabilities (CVs) for data points (excluding outliers) were less than $10 \%$ and $15 \%$, respectively. In order to analyze salivary cortisol differences, the area under the curve from ground (AUCg) for each participant was computed (Pruessner, Kirschbaum, Meinlschmid, \& Hellhammer, 2003). AUCg was computed in Excel and 2-tailed independent group t-tests were applied using SPSS v. 18.0.

Pure spit estrogen samples were collected with the same at-home sampling kits presented above. Samples were completed at the 10am mark for each of the 2 consecutive days. The saliva samples were analyzed for estradiol using ELISA techniques described by Salimetrics (at salimetrics.com). Intra-assay coefficients of variation on one estrogen measurement/participant less than $0.43(\mathrm{CV}(\%)=4.03$, Range: $0.148-19)$. Group differences in estrogen levels were assessed by a 2-tailed independent t-tests using SPSS v. 18.0.

\subsection{Scanning sessions}

Images were acquired using a 1.5 Tesla Siemens Magnetom Symphony MR scanner. Participants were instructed to lie on their back with their head secured in a standard head holder and to stay as still as possible while in the scanner. A gradient echo localizer was acquired and used to prescribe a subsequent 3D FLASH (Fast Low Angle Shot) spoiled gradient sequence (TR/TE 22/9.2ms, flip angle $30^{\circ}$, field of view (FOV) 256x256 mm analyses). T1-weighted images were processed and examined using SPM8 software (Wellcome Department of Imaging Neuroscience Group, London, UK; http://www.fil.ion.ucl.ac.uk/spm) and the VBM8 toolbox (http://dbm.neuro.uni-ena.de/vbm.html), set with default parameters. Images were bias-corrected, tissue classified, and registered using linear (12-parameter affine) and non-linear transformations (warping), within a unified model (Ashburner\&Friston, 2005). Subsequently, analyses were performed on grey matter (GM) and white matter (WM) segmented volumes, which were multiplied by the non-linear components derived from the normalization matrix in order to preserve actual GM and WM values locally (modulated GM and WM volumes). The modulated volumes were smoothed with a Gaussian kernel of $12 \mathrm{~mm}$ full width at half maximum (FWHM).

Total WM, GM and CSF volumes were extracted per participant and correlation analyses were computed in SPSS along variables such as: age, IQ and the six neuropsychological cognitive domain scores. Voxel-wise GM and WM group differences between $\mathrm{BC}$ patients and matched controls were examined using independent-sample t-tests. This technique uses means from 2 samples to address if the observed signal change at every voxel occurred by chance or if this change is statistically significant. In addition, these independent sample t-tests were individually performed with separate covariates (days since surgery, diurnal cortisol, depression scores, anxiety scores, IQ) in order to isolate the influences of suspected confound variables on group differences. Such a technique focuses on mean, partialling out activation due to a variable of no interest that could influence the overall activation pattern. Regression analyses of all participants, patients alone and controls alone were also computed along the same confound variables in order to investigate sample heterogeneity. This technique models the effect of one independent variable on one dependent variable to describes the relationship or allows to predict one variable from the other. For both analyses, voxels with GM or WM values of less than 0.1 (absolute threshold masking) were excluded in order to avoid possible edge effects between different tissue types.

Whole brain and ROI investigations were conducted at a set threshold of $\mathrm{p}_{\text {uncorr. }}=0.001$ uncorrected, with a cluster-wise correction at $p_{\mathrm{FWE}}=0.05$ and a set cluster size larger than 10 voxels. ROIs investigated in this study were selected from several sources: the affected regions in previous post-chemotherapy structural and functional 
studies (Inagaki et al., 2007, McDonald et al., 2010, Abraham et al., 2008, Deprez et al., 2010, Kreukels et al., 2005, Kreukels et al., 2006, Kreukels et al., 2008, Silverman et al., 2007, Saykin et al., 2006, de Ruiter et al., 2010, Raffa \& Tallarida, 2010),and related papers considered in light of possible confound variable effects, such as stress and cytokine activity. ROIs extracted included bilateral: frontal lobe, precentralgyrus, cingulate gyrus, parahippocampus, hippocampus, insula, thalamus, basal ganglia, temporal lobe, parietal lobe, precuneus, occipital lobe, brainstem and cerebellum. Significant results presented are both un-adjusted and adjusted for multiple comparisons. A Bonferroni adjustment with 28 comparisons lowers the alpha to $3.57^{-5}$ with a significant z-value now of 3.97 .

\section{Results}

\subsection{Demographic and clinical data}

Correlations were computed to investigate relationships between demographic data and neuropsychological variables. Age negatively correlated with attention $(\mathrm{r}(46)=-0.311, \mathrm{p}=0.035)$, reasoning $(\mathrm{r}(46)=-0.418, \mathrm{p}=$ $0.004)$, and processing speed $(\mathrm{r}(46)=-0.531, \mathrm{p}<0.001)$ with younger participants scoring overall higher on tests comprising these cognitive domains. The Wechsler test of Adult Reading positively correlated with five out of the six cognitive domains: attention $(\mathrm{r}(46)=0.486, \mathrm{p}=0.001)$, visual memory $(\mathrm{r}(46)=0.332, \mathrm{p}=0.026)$, reasoning $(\mathrm{r}(46)=0.295, \mathrm{p}=0.049)$, verbal short-term memory $(\mathrm{r}(46)=0.459, \mathrm{p}=0.002)$, as well as processing speed $(\mathrm{r}(46)=0.447, \mathrm{p}=0.002)$. Individuals with higher Wechsler scores also had higher scores in these cognitive domains. Additionally, verbal memory positively correlated with reasoning $(\mathrm{r}(46)=0.353, \mathrm{p}=0.016)$, attention correlated with visual memory $(r(46)=0.496, p=0.000)$, reasoning $(r(46)=0.596, p=0.000)$ as well as processing speed $(\mathrm{r}(46)=0.551, \mathrm{p}=0.000)$ and visual memory correlated with processing speed $(\mathrm{r}(46)=0.314$, $\mathrm{p}=0.033)$. As expected, BDI scores positively correlate with BAI scores $(\mathrm{r}(46)=0.342 ., \mathrm{p}=0.020)$. A negative correlation was revealed between BDI scores and the processing speed domain $(r(46)=-0.368, p=0.012)$ while a similar negative correlation was shown between BAI scores and verbal short-term memory $(\mathrm{r}(46)=-0.362, \mathrm{p}=$ $0.013)$.

Table 1 summarizes demographic and clinical characteristics for the $\mathrm{BC}$ and the healthy control groups. Estimated IQ was assessed by the Wechsler Adult Reading Task, and no significant group differences between patients and controls were revealed $(\mathrm{t}(44)=-1.312, \mathrm{p}=0.197)$. No significant differences were revealed between groups considering menopausal status, with half the sample being post-menopausal. The BDI revealed larger mean scores in patients $(8.3)$ compared to controls $(3.8)(\mathrm{t}(44)=2.299, \mathrm{p}=0.026)$. Similarly, the BAI showed larger scores in patients (7.8) compared to controls $(4.1)(\mathrm{t}(44)=2.090, \mathrm{p}=0.042)$. There were no significant group differences in any of the six cognitive domains or the self-esteem measures.

\subsection{Biological measures}

Patient blood work revealed average values in the normal range: Hemoglobin (HGB): 134 grams/L, White blood cells (WBC): $7 \times 10^{9} / \mathrm{L}$, Neutrophils: $4.21 \times 10^{9} / \mathrm{L}$. Patients and controls did not differ significantly on salivary estrogen levels $(\mathrm{t}(25)=0.835, \mathrm{p}>0.412)$ with average values being 6.07 (StDev 3.89) and 4.98 (StDev 2.89), respectively. Similarly, group differences concerning AUCg values of diurnal salivary cortisol were also non-significant $(\mathrm{t}(25)=-1.308, \mathrm{p}>0.203)$, with average AUCgat 12.7 (StDev 5.41) and 16.1 (StDev 8.68) respectively for patients and controls. Each subject's diurnal cortisol index, reflecting average diurnal cortisol excursion, ranged from 0 to $0.973 \mathrm{ug} / \mathrm{dL}$, mean $=0.144$ (StDev 0.159). See Figure 1 graph of diurnal cortisol rhythms for $\mathrm{BC}$ patients and matched controls.

\subsection{Total volume correlations with demographic, neuropsychological domains and cortisol}

Mean segmented volumes for GM, WM, CSF and total brain volume were calculated for both patients and controls. Patients' volumes were $\mathrm{GM}=529.05(\mathrm{StDev} 46.98), \mathrm{WM}=579.92(\mathrm{StDev} 68.03)$ and $\mathrm{CSF}=203.31$ (StDev 29.95), with total brain volume of 1312.28 (StDev 116.27). Volumes in controls were $\mathrm{GM}=530.09$ (StDev 56.69), $\mathrm{WM}=600.51$ (StDev 49.46) and $\mathrm{CSF}=209.61$ (StDev 34.94), with total brain volume of 1340.22 (106.02). Across all participants, there were positive correlations between GM and $\mathrm{WM}(\mathrm{r}(46)=0.634, \mathrm{p}=0.01)$, as well as between brain total volume with GM $(\mathrm{r}(46)=0.835, \mathrm{p}=0.01), \mathrm{WM}(\mathrm{r}(46)=0.894, \mathrm{p}=0.01)$ and CSF $(\mathrm{r}(46)=0.450, \mathrm{p}=0.01)$. There were negative correlations between GM and age $(\mathrm{r}(46)=-0.413, \mathrm{p}=0.01), \mathrm{WM}$ and BDI scores $(\mathrm{r}(46)=-0.308, \mathrm{p}=0.05)$ as well as CSF and processing speed $(\mathrm{r}(46)=-0.368, \mathrm{p}=0.05)$. A positive correlation was revealed between GM and total neuropsychology scores (collapsed 6 domains) $(\mathrm{r}(46)=$ 0.299, $\mathrm{p}=0.05)$, as well as between CSF and age $(\mathrm{r}(46)=0.336, \mathrm{p}=0.05)$. Across controls only, there were positive correlations between GM and $\mathrm{WM}(\mathrm{r}(46)=0.643, \mathrm{p}=0.01)$, as well as between total brain volume with $\mathrm{GM}(\mathrm{r}(46)=0.864, \mathrm{p}=0.01), \mathrm{WM}(\mathrm{r}(46)=0.848, \mathrm{p}=0.01)$ and $\operatorname{CSF}(\mathrm{r}(46)=0.431, \mathrm{p}=0.05)$. There was a negative correlation between GM and age $(\mathrm{r}(46)=-0.537, \mathrm{p}=0.01)$, yet positive correlations between CSF and 
age $(r(46)=0.438, p=0.05)$ as well as GM and visual memory domain scores $(r(46)=0.414, p=0.05)$. Across patients only, there were positive correlations between GM and WM $(\mathrm{r}(46)=0.681, \mathrm{p}=0.01)$, as well as between total brain volume with GM $(\mathrm{r}(46)=0.832, \mathrm{p}=0.01)$, WM $(\mathrm{r}(46)=0.930, \mathrm{p}=0.01)$ and $\operatorname{CSF}(\mathrm{r}(46)=0.464, \mathrm{p}=$ $0.05)$. No other significant correlations were revealed.

\subsection{Anatomical MRI analysis- Grey matter}

\subsubsection{Between-group analyses (GM)}

There were no between-group differences in GM volume in both whole brain and ROI analyses when computing independent t-tests. Addition of the covariates did not significantly modify the results.

\subsubsection{Regression Analyses (GM)}

See Table 2 for significance, ROI, MNI coordinates, cluster sizes, $t$ values and $z$ values. The table was grouped according to regression analyses with all participants, controls only and patients only along the five confound factors.

\subsubsection{All participants (GM)}

Regression analysis of the BDI scores computed with all study participants indicated smaller volume in the left cuneus with increasing depression index scores. Larger BAI scores were associated with larger volumes in the right parahippocampus and the right lentiform nucleus. Regression along the Wechsler assessment revealed larger volumes in the left superior frontal gyrus, left middle frontal gyrus, left inferior frontal gyrus, and left middle occipital gyrus.

\subsubsection{Controls only (GM)}

Regression analysis with controls along BDI scores revealed larger volumes in the left inferior parietal lobule, left inferior temporal gyrus and right middle orbital frontal gyrus with larger scores in this depression index. Similarly, larger BAI scores were associated with larger volumes in the left middle frontal gyrus and right hippocampus. Regression along Wechsler test scores indicated larger volumes in the left superior frontal gyrus, left cuneus, left putamen, as well as right superior occipital gyrus with larger scores on this IQ measure.

\subsubsection{BC patients only (GM)}

Regression analysis of BC patients only along "days since surgery" revealed increased volume in left and right thalamus with more post-surgery time passed. Meanwhile, decreased volume was reported in the left cuneus with more days between surgery and scan dates. Regression along BDI scores revealed smaller volumes in the right inferior and middle occipital gyri with larger depression scores. Larger BAI scores were associated with significantly larger volumes in the right lentiform nucleus. Regression along Wechsler scores revealed larger volumes in the left supramarginalgyrus, right inferior parietal lobule, and left posterior cerebellar declive.

\subsection{Anatomical MRI analysis- white matter}

\subsubsection{Between-group analyses (WM)}

No significant group differences in whole brain WM values were revealed between patients and controls when computing independent $t$-tests. See table 3 for significance, ROI, MNI coordinates, cluster sizes, $t$ values and $z$ values. However, ROI analyses extracted group differences between patients and controls with patients showing smaller WM volumes in bilateral inferior frontal, left pre and postcentralgyri, left insula, left striatum (putamen and caudate), right supramarginalgyrus, left inferior parietal, right middle temporal gyrus, left precuneus and left corpus callosum (Figure 2). To control for any effects of potentially contributing factors, selected covariates were individually added to the model for analyses. Overall, patients revealed larger volumes with the addition of certain covariates such as "days since surgery", BDI scores and BAI scores. Meanwhile, all other significant findings (with or without the addition of a covariate) included smaller WM volumes at baseline in BC patients compared to controls.

\subsubsection{Regression analyses (WM)}

See Table 4 for significance, ROI, MNI coordinates, cluster sizes, $\mathrm{t}$ values and $\mathrm{z}$ values. The table was grouped according to regression analyses with all participants, controls only and patients only along the 5 confound factors.

\subsubsection{All participants (WM)}

Regression analyses of all study participants along cortisol revealed increased volume in the left precuneus and left cuneus. Regression along BDI scores revealed both positive and negative relationships with WM volume. 
Higher BDI scores were associated with larger volumes in the left inferior temporal gyrus and left superior temporal pole. Meanwhile, higher BDI scores were associated with smaller volumes in the right superior frontal gyrus, left medial frontal gyrus, right inferior frontal operculum, bilateral anterior cingulate gyri, left insula, right caudate, left superior parietal lobule, left precuneus, right posterior cerebellar declive, left posterior cerebellar tonsil and left anterior cerebellar culmen. Regressions along BAI scores revealed increased left angular gyrus volume and decreased volume in the left inferior orbital frontal gyrus with larger anxiety scores. Higher scores on the Wechsler measure were associated with larger volumes in the right precentralgyrus, right postcentralgyrus, right precuneus and left cuneus.

\subsubsection{Controls only (WM)}

Regression analysis with controls only along BDI scores revealed decreased volume in the left middle frontal gyrus and left precentralgyrus with increasing scores. Additionally, larger volumes were revealed in the left posterior cerebellar declive with larger BAI scores. Finally, larger volumes were revealed in the right precuneus, right posterior cingulate gyrus, right caudate and left cuneus with larger IQ scores (Wechsler).

\subsubsection{BC patients only (WM)}

Regression analysis of BC patients only with "days since surgery" revealed increased volume in left insula and putamen with more time passed between surgery and the scanning session. Meanwhile, smaller volumes were reported in the right inferior frontal gyrus with more post-surgery days. Regression along cortisol AUCg showed larger volumes in the right middle and superior frontal gyri, right cingulate gyrus, left rolandic operculum and left anterior cerebellar culmen. Investigations along BDI scores revealed smaller volumes in the right inferior frontal and right brain stem with larger depression scores. Larger BAI scores were associated with significantly larger volumes in the left angular gyrus but smaller volumes in the superior medial frontal gyrus. Regression along IQ scores (Wechsler) revealed an association between smaller right and left corpus callosum volumes and larger IQ scores.

\section{Discussion}

Previous research has indicated that chemotherapy-treated cancer patients experience a post-treatment cognitive decline. However, before assessing cognitive deficits precipitated by chemotherapy, one must better understand these patients at baseline. While there are few systemic studies examining distinctions between patients and matched controls at baseline, these do suggest group differences in brain function and structure even before treatment commences (Cimprich et al., 2010, Vardy et al., 2007). Such baseline distinctions between newly diagnosed $\mathrm{BC}$ patients and matched controls are supported by the current results.

No group differences regarding GM were revealed in this study, yet there were significant differences in WM volume between patients and controls. The latter volumetric difference is interesting, considering a strong focus on WM changes in the study of chemofog. Therefore, some of the WM differences attributed to post-treatment effects may already be manifesting at baseline. It is important to remember that this study applied both whole brain and ROI analyses. While whole brain results were not significant, ROI investigations based on post-chemotherapy findings yielded significant group differences. ROI analyses are appropriate for investigations of subtle group differences in brain volume when previous research indicates target regions that warrant further exploration. Whole brain analyses are extremely stringent and increase type II error since all voxels in the brain are considered. ROI analyses consider a smaller number of voxels contained to a limited masked area, which increases the chance of uncovering subtle group differences. While this technique increases the odds of committing a type I error, this can partially be controlled for with more stringent thresholding. Therefore, other structural MRI studies may not have uncovered baseline group differences due to the fact that their investigations were limited to "whole brain" analyses. The current paper revealed smaller pre-chemotherapy WM volumes in patients compared to controls in widespread regions in the frontal, parietal and limbic regions using ROI analyses.

This paper is also the first and largest baseline structural imaging study to systematically covary a range of suspected confound variables in this patient population. A variety of covariates were examined such as diurnal cortisol, depression and anxiety scores, IQ scores as well as days since surgery. The addition of covariates in the independent t-test did not unveil volumetric group differences concerning GM, but considerably modified WM results. First, when considering days since surgery as a covariate, patients revealed previously unobserved larger WM volumes compared to controls in left middle occipital gyrus and right parahippocampus. Meanwhile, when considering smaller patient WM volumes compared to controls, addition of this particular covariate eliminated all baseline differences and attenuated the group difference in the left insula. A smaller left temporal pole in the patient cohort was also introduced with this covariate, this region being highly connected with both the limbic 
system and the insula (Chabardès, Kahane, Minotti, Hoffmann, \& Benabid, 2002). Interestingly, the left temporal pole has also shown decreased glucose metabolic rates with increasing number of chemotherapy cycles (Baudino et al., 2011). It is possible that anesthesia agents or post-surgery cytokines first impact this region, and these adverse effects are then sustained and enhanced with chemotherapy treatment. Considering that BC patients are usually older, it is also possible that these effects exacerbated volumetric and functional declines seen in this region which also take place with normal aging (Bergfield et al., 2010; Dupont, 2002, Eberling et al., 1995; Goldman-Rakic \& Brown, 1981). Overall, the number of days since surgery impacts WM volume in BC patients.

Abnormal diurnal cortisol patterns have been reported among women with BC (Abercrombie et al., 2004; Spiegel, Giese-Davis, Taylor, \& Kraemer, 2006), with patients showing "flattened cortisol rhythms" (Spiegel et al., 2006). Flatter patterns of cortisol secretion have been associated with impaired negative feedback of the HPA axis (Spiegel et al., 2006). Similarly, a flattened response was observed in patients in the present study, as revealed in a graph investigation of averaged areas under the curve (AUC). However, there was no significant difference in the AUCg between patient and control groups, a result which is supported by another fMRI study (Kesler et al., 2009) who considered "distress measures" such as salivary cortisol in their investigation of verbal declarative memory capacities in patients after treatment. It is important to note that both the Kesleret al. (2009) study, as well as the current study examined diurnal salivary cortisol levels in small populations, potentially too small to uncover significant group differences (Practical constraints in the current study prevented many of the participants from completing salivary sampling.) Yet, in this study, the addition of diurnal cortisol values as a covariate in the t-test analysis only maintained volumetric group differences in the left pre- and post-central gyri seen in the no-covariate condition and eliminated all other group differences. Interestingly, this covariate additionally introduced new WM group differences with smaller patient volumes in the left middle temporal, right superior frontal, right inferior parietal (angular) lobule and right middle occipital gyrus. Therefore, consideration of cortisol not only modified the no-covariate model, but also introduced new group differences in widespread regions of the brain. Additionally, the standard deviations were rather large in this patient group, especially for the morning sampling time points where the group differences are the largest. Future investigations of baseline cortisol differences between $\mathrm{BC}$ patients and controls should be conducted in a larger sample. Patients are in a high stress situation with a new cancer diagnosis, therefore it is not surprising that they are showing group differences compared to controls when cortisol, an indicator of stress, is being considered.

When the BDI and the BAI scores were added in separate group comparisons as covariates, no new regions were introduced compared to the no-covariate condition. However, both inventories attenuated volumetric differences manifesting as smaller WM volumes in patients compared to controls. While there were subtle discrepancies in the regions affected by each inventory, there was considerable overlap given the correlation of these factors. What is interesting is that, while participants as a whole scored in the mild range for both inventories, patients had significantly larger scores compared to controls. Such a divergence between groups could be the consequence of a variety of factors present in the patients' lives such as the stress of a new diagnosis and/or facing disease side-effects including upcoming cancer treatment. Hence, even a subtle but significant difference in these "mild" scores should be investigated at baseline, as this study reveals influences both behaviourally and in the brain.

Finally, the addition of the IQ covariate in the model does not uncover new group differences, yet modifies the no-covariate model. More investigations are necessary before drawing a conclusion on the relationship between baseline factors in cancer patients, IQ and brain volume.

The effects of confound factors which may contribute to the heterogeneity of a population, can be considered in regression analyses. The exact regions that modulate volume along a particular variable are presented in Tables 2 and 4 , but these and their functions will not be further discussed. While within-sample modulations along variables are expected, attention must be drawn to the minimal overlap in regions seen in patient and control groups (23 participants in each group) for each separate regression analysis. Patients showed different volumetric variations along factors compared to controls. Additionally, new anatomical variations along the factors in question were introduced when performing regressions with all participants (patients and controls together, 46 subjects). Therefore with all participants, new areas were uncovered that were not revealed in single group analyses (patients alone or controls alone). When the sample is doubled, more areas are extracted which highlights the need for larger populations in chemofog studies. Also important to consider, while heterogeneity is to be expected in both patient and control groups alike, the patient group revealed significantly more within-group variability compared to controls along certain confound factors. This is particularly evident in the 
cortisol AUCg and WM volume regression analysis where patients showed larger volumes associated with larger AUCg in widespread frontal regions and cerebellum, while controls had no within-group variability.

The regression analysis considering "days since surgery" in the patient cohort revealed further within-group variability. With more days between the surgery and scan dates, patients revealed larger left insula and putamen WM volumes as well as bilateral thalamus GM volumes. Meanwhile, with fewer days post-surgery, patients showed smaller right inferior frontal WM volume. Such results are further support for a potential effect of surgery on brain anatomy, possibly due to negative effects of anesthesia (Monk et al., 2008) and/or of cytokine activity (Vardy et al., 2007). Whether patients are "regaining" anatomical volume or these regional time-dependent increases are compensatory in nature, it remains that days since surgery seems to contribute to variability in the patient sample. This particular finding could help explain some of the variability concerning baseline measures in the recently published prospective studies. If a study recruits patients who underwent baseline MRI scans soon after surgery, there may be volumetric differences compared to a patient sample that was scanned much later after surgery. Additionally, while one may assume that post-surgery patients are "returning" to a baseline that resembles controls, such recuperation could take much longer than time allotted in these studies, which is usually about one month. It is important to note that in some cases, a complete recuperation might be an erroneous assumption as previous studies have indicated long-term cognitive deficits (Monk et al., 2008). It is interesting to consider that confound variables could already manifest at baseline, thereby suggesting that some of the post-treatment results could in fact be contaminated by these effects.

In conclusion, this study suggests that investigating only whole brain volumetric differences between controls and $\mathrm{BC}$ patients is not sufficient to truly understand this multi-factorial patient population. The differences may be subtle and the results from this paper support the use of rigorous and varied statistical measures to expose these effects. Region of interest investigations helped uncover differences between patients and matched controls, focusing on regions that are consistently reported in post-chemotherapy populations. These group differences were only observed in WM volumes, a prominent focus for post-chemotherapy studies. Hence, there is reason to suspect that some of the adverse effects attributed to chemotherapy are already present at baseline, and these are potentially exacerbated by the treatment. This was also supported by the modifications to results observed when adding covariates to the analyses. These confound variables, particularly post-surgical time to scanning and cortisol measures should be included in future studies as primary variables of interest. Additionally, grouping patients together for between-group comparisons (such as t-test) washed out important subtle variations in the patient population. This paper suggests that regression analyses of patients alone can help uncover small changes/differences within the sample along important variables such as days since surgery. Overall, while each suspected factor in this study was applied as a covariate in a separate t-test or regression analysis, it is acknowledged that these do not present alone and likely work in conjunction. Baseline assessments are important to validate each $\mathrm{BC}$ patient's personal experiences. While chemotherapy has been shown to affect cognition and the brain, there are a number of obstacles that patients must face even before the commencement of treatmentwhether at the biological level with elevated cytokine activity and the side-effects of surgery or at the personal level with increased feelings of stress, anxiety and depression. Finally, this paper provides preliminary but compelling evidence of neuroanatomical differences between $\mathrm{BC}$ patients and controls, prior to chemotherapy. Such findings are important since volumetric differences/changes in the brain could lead to functional impairments in cognitive processing.

\section{References}

Abercrombie, H. C., Giese-Davis, J., Sephton, S., Epel, E. S., Turner-Cobb, J. M., \& Spiegel, D. (2004). Flattened cortisol rhythms in metastatic breast cancer patients. Psychoneuroendocrinology, 29, 1082-1092. http://dx.doi.org/10.1016/j.psyneuen.2003.11.003

Abraham, J., Haut, M. W., Moran, M. T., Filburn, S., Lemiuex, S., \& Kuwabara, H. (2008). Adjuvant chemotherapy for breast cancer: effects on cerebral white matter seen in diffusion tensor imaging. Clinical Breast Cancer, 8, 88-91. http://dx.doi.org/10.3816/CBC.2008.n.007

Ahles T. A., Saykin A. J., Furstenberg C. T., Cole B., Mott L. A., Skalla K., \& Silberfarb P. M. (2002). Neuropsychologic impact of standard-dose systemic chemotherapy in long-term survivors of breast cancer and lymphoma. Journal of Clinical Oncologly, 20, 485-493. http://dx.doi.org/10.1200/JCO.20.2.485

Ahles, T. A., Tope, D. M., Furstenberg, C., Hann, D., \& Mills, L. (1996). Psychologic and neuropsychologic impact of autologous bone marrow transplantation. Journal of Clinical Oncology, 14, 1457-1462. http://dx.doi.org/10.1016/j.neuroimage.2005.02.018 
Army Individual Test Battery. (1944). Manual for directions and scoring. Washington, DC: War Department, Adjutant General's Office.

Ashburner, J., \& Friston, K. J. (2005).Unified segmentation. Neuroimage, 26, 839-851.

Backhaus, J., Junghanns, K., \& Hohagen, F. (2004). Sleep disturbances are correlated with decreased morning $\begin{array}{lllll}\text { awakening salivary } & \text { cortisol. } & \text { Psychoneuroendocrinology, } & 29, & 1184-1191 .\end{array}$ http://dx.doi.org/10.1016/j.psyneuen.2004.01.010

Baudino, B., D'Agata, F., Castellano, G., et al. (2011). Chemotherapy effects on brain glucose metabolism at rest. Nature Precedings. [Online] Available: http://precedings.nature.com/documents/5637/version/1

Beck, A. T., Steer, R. A., \& Brown, G. K. (1996). Beck Depression Inventory-Second Edition Manual. San Antonio, TX: Psychological Corporation.

Beck, A. T. \& Steer, R. A. (1990). Beck Anxiety Inventory Manual. San Antonio, TX: Psychological Corporation.

Behl, C. (2002). Oestrogen as a neuroprotective hormone.Nature Reviews Neuroscience, 3, 433-442.

Bender, C. M., Sereika, S. M., Berga, S. L., et al. (2006). Cognitive impairment associated with adjuvant therapy in breast cancer. Psychooncolog, 15, 422-430. http://dx.doi.org/10.1002/pon.964

Benedict, R. H. B. (1997). Brief visuospatial memory test revised. Odessa, FL: Psychological Assessment Resources, Inc.

Benton, A. L., Hamsher, K., \& Sivan, A. B. (1994). Multilingual aphasia examination. (3rd ed). Iowa City, IA: AJA.

Bergfield, K. L., Hanson, K. D., Chen, K., et al. (2010). Age-related networks of regional covariance in MRI gray matter: reproducible multivariate patterns in healthy aging. Neuroimage, 49, 1750-1759. http://dx.doi.org/10.1016/j.neuroimage.2009.09.051

Berglund, G., Bolund, C., Fornander, T., Rutqvist, L. E., \& Sjoden, P. (1991). Late effects of adjuvant chemotherapy on quality of life among breast cancer patients. European Journal of Cancer, 27, 1075-1081. http://dx.doi.org/10.1016/0277-5379(91)90295-O

Boone, B. L., Miller, I. M., Lesser, E. H., \& D’ Elia, L. (1990). Performance on frontal lobe tests in healthy, older individuals. Developmental Neuropsychology, 6, 215-223. http://dx.doi.org/10.1080/87565649009540462

Brandt, J., \& Benedict, R. H. B. (2001). Hopkins verbal learning test revised. Professional manual. Lutz, FL: Psychological Assessment Resources, Inc.

Bremner, J. D., Southwick, S. M., \& Charney, D. S. (1999). The neurobiology of posttraumatic stress disorder: An integration of animal and human research. In: Bremner, J.D., Saigh, P.A., (Eds.), Posttraumatic Stress Disorder: A Comprehensive Text (103-143). New York: Allyn \& Bacon.

Brezden, C., Phillips, K. A., Bunston, T., \& Tannock, I. F. (2000). Cognitive function in breast cancer patients receiving adjuvant chemotherapy. Journal of Clinical Oncology, 18, 2695-2701.

Brown, M. S., Stemmer, S. M., Simon, J. H., et al. (1998). White matter disease induced by high-dose chemotherapy: longitudinal study with MR imaging and proton spectroscopy. American Journal of Neuroradiology, 19, 217-221.

Castellon, S. A., Ganz, P. A., Bower, J. E., Petersen, L., Abraham, L., \& Greendale, G. A. (2004). Neurocognitive performance in breast cancer survivors exposed to adjuvant chemotherapy and tamoxifen. Journal of Clinical and Experimental Neuropsychology, 26, 955-969. http://dx.doi.org/10.1080/13803390490510905

Chabardès, S., Kahane, P., Minotti, L., Hoffmann, D., \& Benabid, A. L. (2002). Anatomy of the temporal pole region. Epileptic Disorders, 4, 9-15.

Cimprich, B., Reuter-Lorenz, P., Nelson, J., et al. (2010). Prechemotherapy alterations in brain function in women with breast cancer. Journal of Clinical and Experimental Neuropsychology, 32, 324- 331. http://dx.doi.org/10.1080/13803390903032537

Correa, D. D., \& Ahles T. A. (2007). Cognitive adverse effects of chemotherapy in breast cancer patients. Current Opinion in Supportive Palliative Care, 1, 57-62. http://dx.doi.org/10.1097/SPC.0b013e32813a328f 
de Ruiter, M. B., Reneman, L., Boogerd, W., et al. (2011). Cerebral hyporesponsiveness and cognitive impairment 10 years after chemotherapy for breast cancer. Human Brain Mapping, 32, 1206-1219. http://dx.doi.org/10.1002/hbm.21102

Deprez, S., Amant, F., Yigit, R., et al. (2010). Chemotherapy-induced structural changes in cerebral white matter and its correlation with impaired cognitive functioning in breast cancer patients. Human Brain Mapping, 32, 480-493. http://dx.doi.org/10.1002/hbm.21033

Dijkstra, J. B., Houx, P. J., \& Jolles, J. (1999). Cognition after major surgery in the elderly: test performance and complaints. British Journal of Anaesthesia, 82, 867-874.

Dodds, C., \& Allison, J. (1998). Postoperative cognitive deficit in the elderly surgical patient.British. Journal of Anaesthesia, 81, 449-462.

Dupont, S. (2002). Investigating temporal pole function by functional imaging. Epileptic Disorders, 4, 17-22.

Eberling, J. L., Nordahl, T. E., Kusubov, N., Reed, B. R., Budinger, T. F., \& Jagust, W. J. (1995). Reduced temporal lobe glucose metabolism in aging. Journal of Neuroimaging, 5, 178-182.

Ferguson, R. J., McDonald, B. C., Saykin, A. J., \& Ahles, T. A. (2007). Brain structure and function differences in monozygotic twins: possible effects of breast cancer chemotherapy. Journal of Clinical Oncology, 25, 3866-3870. http://dx.doi.org/10.1200/JCO.2007.10.8639

Goldman-Raki,c P. S., \& Brown, R. M. (1981). Regional changes of monoamines in cerebral cortex and subcortical structures of aging rhesus monkeys. Neuroscience, 6, 177-187. http://dx.doi.org/10.1016/0306-4522(81)90053-1

Gottschalk, L. A., Holcombe, R. F., Jackson, D., \& Bechtel, R. J. (2003). The effects of anticancer chemotherapeutic drugs on cognitive function and other neuropsychiatric dimensions in breast cancer patients. Methods and Findings in Experimental and Clinical Pharmacology, 25, 117-122. http://dx.doi.org/10.1358/mf.2003.25.2.723685

Gronwall, D. M. A. (1977). Paced auditory serial addition task: A measure of recovery from concussion. Perceptual and Motor Skills, 44,367-373. http://dx.doi.org/10.2466/pms.1977.44.2.367

Gualtieri, C. T., \& Johnson, C. T. (2006). Reliability and validity of a computerized neurocognitive test battery, CNS Vital Signs. Archives of Clinical Neuropsychology, 21, 623-643. http://dx.doi.org/10.1016/j.acn.2006.05.007

Hurria, A., Rosen, C., Hudis, C., Zuckerman, E., Panageas, K. S., Lachs, M. S., ... Holland, J. (2006). Cognitive function of older patients receiving adjuvant chemotherapy for breast cancer: A pilot prospective longitudinal study. Journal of the American Geriatric Society, 54, 925-931. http://dx.doi.org/10.1111/j.1532-5415.2006.00732.x

Inagaki, M., Yoshikawa, E., Matsuoka, Y., et al. (2007). Smaller regional volumes of brain gray and white matter demonstrated in breast cancer survivors exposed to adjuvant chemotherapy. Cancer, 109, 146-156. http://dx.doi.org/10.1002/cncr.22368

Jenkins V, Shilling V, Deutsch G, et al. (2006). A 3-year prospective study of the effects of adjuvant treatments on cognition in women with early stage breast cancer. British Journal of Cancer, 94, 828-834. http://dx.doi.org/10.1038/sj.bjc.6603029

Kesler, S. R., Bennett, F. C., Mahaffey, M. L., \& Spiegel, D. (2009). Regional brain activation during verbal declarative memory in metastatic breast cancer. Clinical Cancer Research, 15, 6665-6673. http://dx.doi.org/10.1158/1078-0432.CCR-09-1227

Kirschbaum, C., \& Hellhammer, D. H. (1994). Salivary cortisol in psychoneuroendocrine research: recent $\begin{array}{llll}\text { developments and } \quad \text { applications. } & \text { Psychoneuroendocrinology, } & 19, & 333 .\end{array}$ http://dx.doi.org/10.1016/0306-4530(94)90013-2

Krampen, G. (1991). Fragebogen zu Kompetenz und Kontrollueberzeugungen (FKK). Göttingen: Hogrefe.

Kreukels, B. P., Hamburger, H. L., de Ruiter, M. B., et al. (2008). ERP amplitude and latency in breast cancer survivors treated with adjuvant chemotherapy. Clinical Neurophysiology, 119, 533-541. http://dx.doi.org/10.1016/j.clinph.2007.11.011 
Kreukels, B. P., Schagen, S. B., Ridderinkhof, K. R., Boogerd, W., Hamburger, H. L., \& van Dam, F. S. (2005). Electrophysiological correlates of information processing in breast-cancer patients treated with adjuvant chemotherapy. Breast Cancer Research and Treatment, 94, 53-61. http://dx.doi.org/10.1007/s10549-005-7093-3

Kreukels, B. P., Schagen, S. B., Ridderinkhof, K. R., Boogerd, W., Hamburger, H. L., Muller, M. J., \& van Dam, F. S. (2006). Effects of high-dose and conventional-dose adjuvant chemotherapy on long-term cognitive sequelae in patients with breast cancer: an electrophysiologic study. Clinical Breast Cancer, 7, 67-78. http://dx.doi.org/10.3816/CBC.2006.n.015

Kumari, M., Badrick, E., Chandola, T., et al. (2010). Measures of social position and cortisol secretion in an aging population: findings from the Whitehall II study. Psychosomatic Medicine, 72, 27-34. http://dx.doi.org/10.1097/PSY.0b013e3181c85712

Lord, C., Buss, C., Lupien, S. J., \& Pruessner, J. C. (2008). Hippocampal volumes are larger in postmenopausal women using estrogen therapy compared to past users, never users and men: A possible window of opportunity effect. Neurobiology of Aging, 29, 95-101. http://dx.doi.org/10.1016/j.neurobiolaging.2006.09.001

Lupien, S. J., Gillin, C. J., \& Hauger, R. L. (1999). Working memory is more sensitive than declarative memory to the acute effects of corticosteroids: a dose-response study in humans. Behavioral Neuroscience, 113, 420-430. http://dx.doi.org/10.1037/0735-7044.113.3.420

MacHale, S. M., Cavanagh, J. T., Bennie, J., Carroll, S., Goodwin, G. M., \& Lawrie, S. M. (1998). Diurnal variation of adrenocortical activity in chronic fatigue syndrome. Neuropsychobiology, 38, 213-217. http://dx.doi.org/10.1159/000026543

Maier, S. F., \& Watkins, L. R. (2003). Immune-to-central nervous system communication and its role in modulating pain and cognition: implications for cancer and cancer treatment. Brain, Behavior, and Immunity, 17, 125-131. http://dx.doi.org/10.1016/S0889-1591(02)00079-X

Mar Fan, H. G., Houédé-Tchen, N., Yi, Q. L., et al. (2005). Fatigue, menopausal symptoms, and cognitive function in women after adjuvant chemotherapy for breast cancer: 1- and 2-year follow-up of a prospective controlled study. Journal Clinical Oncology, 31, 8025-8032.

McDonald, B. C., Conroy, S. K., Ahles, T. A., West, J. D., \& Saykin, A. J. (2010). Gray matter reduction associated with systemic chemotherapy for breast cancer: a prospective MRI study. Breast Cancer Research and Treatment, 123, 819-828. http://dx.doi.org/10.1007/s10549-010-1088-4

McEwen, B. (2002). Estrogen actions throughout the brain. Recent Progress in Hormone Research, 57, 357-84. http://dx.doi.org/10.1210/rp.57.1.357

McEwen, B. S., \& Magarinos, M. (1997). Stress effects on morphology and function of the hippocampus. Annals of the New York Academy of Sciences, 821, 271-284. http://dx.doi.org/10.1111/j.1749-6632.1997.tb48286.x

McEwen, B. S. (1999). Stress and the aging hippocampus. Frontiers in Neuroendocrinology, 20, 49-70. http://dx.doi.org/10.1006/frne.1998.0173

Monk, T. G., Weldon, B. C., Garvan, C. W., et al. (2008). Predictors of cognitive dysfunction after major noncardiac surgery. Anesthesiology, 108, 18-30. http://dx.doi.org/10.1097/01.anes.0000296071.19434.1e

Monteleone, P., \& Maj, M. (2009). Circadian rhythm disturbances in depression: implications for treatment and quality of remission. Medicographia, 31, 132-139.

Noal, S., Levy, C., Hardouin, A., et al. (2011). One-year longitudinal study of fatigue, cognitive functions, and quality of life after adjuvant radiotherapy for breast cancer. International Journal of Radiation Oncology, Biology, Physics, 81, 795-803. http://dx.doi.org/10.1016/j.ijrobp.2010.06.037

Pruessner, J. C., Baldwin, M. W., Dedovic, K., et al. (2005). Self-esteem, locus of control, hippocampal volume, and cortisol regulation in young and old adulthood. Neuroimage, 28, 815-826. http://dx.doi.org/10.1016/j.neuroimage.2005.06.014

Pruessner, J. C., Kirschbaum, C., Meinlschmid, G., \& Hellhammer, D. H. (2003). Two formulas for the computation of the area under the curve represent measures of total hormone concentration versus $\begin{array}{llll}\text { time-dependent } \quad \text { change. } & \text { Psychoneuroendocrinology, } & \text { 28, }\end{array}$ http://dx.doi.org/10.1016/S0306-4530(02)00108-7

Pruessner, J. C., Wolf, O. T., Hellhammer, D. H., et al. (1997). Free cortisol levels after awakening: a reliable biological marker for the assessment of adrenocortical acitvity. Life Sciences, 61, 2539-2549. http://dx.doi.org/10.1016/S0024-3205(97)01008-4 
Pruessner, J. C., Hellhammer, D. H., \& Kirschbaum, C. (1999). Low self-esteem, induced failure and the adrenocortical stress response. Personality and Individual Differences, 27, 477-489. http://dx.doi.org/10.1016/S0191-8869(98)00256-6

Raffa, R. B., \& Tallarida, R. J. (2010). Effects on the visual system might contribute to some of the cognitive deficits of cancer chemotherapy-induced 'chemo-fog'. Journal of Clinical Pharmacy and Therapeutics, 35, 249-255. http://dx.doi.org/ 10.1111/j.1365-2710.2009.01086.x

Rosenberg, M. (1985). Self-concept and psychological well-being in adolescence. In R. L. Leahy (Ed.), The development of the self (205-46). Orlando, FL: The Academic Press.

Sapolsky, R. (1985). A possible mechanism for glucocorticoid toxicity in the hippocampus: increased vulnerability of neurons to metabolic insults. Journal of Neuroscience, 5, 1228-1232.

Saykin, A. J., Ahles, T. A., \& Schoenfeld, J. D. (2003). Gray matter reduction on voxel-based morphometry in chemotherapy-treated cancer survivors. Journal of International Neuropsychology, 9, 246.

Saykin, A. J., McDonald, B. C., Ahles, T., et al. (2006). Altered brain activation following systemic chemotherapy for breast cancer: Interim analysis from a prospective fMRI study. The 34th Annual Meeting of the International Neuropsychological Society, Boston MA.

Schagen, S. B., Muller, M. J., Boogerd, W., Rosenbrand, R. M., van Rhijn, D., Rodenhuis, S., \& van Dam, F. S. (2002). Late effects of adjuvant chemotherapy on cognitive function: a follow-up study in breast cancer patients. Annals of Oncology, 132, 1387-1397. http://dx.doi.org/10.1093/annonc/mdf241

Schagen, S. B., van Dam, F., Muller, M. J., Boogerd, W., Lindeboom, J., \& Bruning, P. F. Cognitive deficits after postoperative adjuvant chemotherapy for breast carcinoma. Cancer, 85, 640-650. http://dx.doi.org/10.1002/(SICI)1097-0142(19990201)85:3\%3C640::AID-CNCR14\%3E3.0.CO;2-G

Scherwath, A., Mehnart, A., Schleimer, B., et al. (2006). Neuropsychological function in high-risk breast cancer survivors after stem-cell supported high-dose therapy versus standard-dose chemotherapy: Evaluation of long-term treatment effects. Annals of Oncology, 17, 415-423. http://dx.doi.org/10.1093/annonc/mdj108

Servaes, P., Verhagen, C., \& Bleijenberg, G. (2002). Relations between fatigue, neuropsychological functioning, and physical activity after treatment for breast carcinoma: Daily self-report and objective behavior. Cancer, 95 , 2017-2026. http://dx.doi.org/10.1002/cncr.10891

Shilling, V., Jenkins, V., Morris, R., Deutsch, G., \& Bloomfield, D. (2005). The effects of adjuvant chemotherapy on cognition in women with breast cancer--preliminary results of an observational longitudinal study.Breast, 14, 142-150. http://dx.doi.org/10.1016/j.breast.2004.10.004

Shilling, V., \& Jenkins, V. (2007). Self-reported cognitive problems in women receiving adjuvant therapy for breast cancer. European Journal of Oncology Nursing, 11, 6-15. http://dx.doi.org/10.1016/j.ejon.2006.02.005

Shughrue, P. J., \& Merchenthaler, I. (2000). Estrogen is more than just a "sex hormone": novel sites for estrogen action in the hippocampus and cerebral cortex. Frontiers in Neuroendocrinology, 21, 95-101. http://dx.doi.org/10.1006/frne.1999.0190

Silverman, D. H. S., Dy, C. J., Castellon, S. A., et al. (2007). Altered frontocortical, cerebellar, and basal ganglia activity in adjuvant-treated breast cancer survivors 5-10 years after chemotherapy. Breast Cancer Researach and Treatment, 103, 303-311. http://dx.doi.org/10.1007/s10549-006-9380-z

Simpson, P. M., Surmon, D. J., Wesnes, K. A., \& Wilcock, G. K. (1991). The Cognitive Drug Research Computerized Assessment System for Demented Patients: A Validated Study. International Journal of Geriatric Psychiatry, 6, 95-102. http://dx.doi.org/ 10.1002/gps.930060208

Spiegel, D., Giese-Davis, J., Taylor, C. B., \& Kraemer, H. (2006). Stress sensitivity in metastatic breast cancer: analysis of hypothalamic-pituitary-adrenal axis function. Psychoneuroendocrinology, 31, 1231-1244. http://dx.doi.org/10.1016/j.psyneuen.2006.09.004

Starkman, M. N., Gebarski, S. S., Berent, S., \& Schteingart, D. E. (1992). Hippocampal formation volume, memory dysfunction, and cortisol levels in patients with Cushing's syndrome. Biological Psychiatry, 32, 756-765. http://dx.doi.org/10.1016/0006-3223(92)90079-F

Stewart, A., Collins, B., MacKenzie, J., Tomiak, E, Verma, S., \& Bielajew, C. (2007). The cognitive effects of adjuvant chemotherapy in early stage breast cancer: A prospective study. Psychooncology, 17, 1-9. 
Tchen, N., Juffs, H. G., Downie, F. P., et al. (2003). Cognitive function, fatigue, and menopausal symptoms in women receiving adjuvant chemotherapy for breast cancer. Journal of Clinical Oncology, 21, 4175-4183. http://dx.doi.org/10.1200/JCO.2003.01.119

Troy, L., McFarland, K., Littman-Power, S., et al. (2000). Cisplatin-based therapy: a neurological and $\begin{array}{lllll}\text { neuropsychological Psychooncology, 29-39. } & \text { review. }\end{array}$ http://dx.doi.org/10.1002/(SICI)1099-1611(200001/02)9:1\%3C29::AID-PON428\%3E3.0.CO;2-Z

Tuxen, M. K., \& Werner, H. S. (1994). Neurotoxicity secondary to antineoplastic drugs. Cancer Treatment Reviews, 20, 191-214. http://dx.doi.org/10.1016/0305-7372(94)90027-2

van Dam, F. S. A. M., Schagen, S. B., Muller, M. J., et al. (1998). Impairment of cognitive function in women receiving adjuvant treatment for high-risk breast cancer: High-dose versus standard-dose chemotherapy. Journal of the National Cancer Institute, 90, 210-218. http://dx.doi.org/10.1093/jnci/90.3.210

Vardy, J., Booth, C., Pond, G. R., et al. (2007). Cytokine levels in patients with colorectal cancer and breast cancer and their relationship to fatigue and cognitive function. The American Society of Clinical Oncology: Patient and Survivor Care, Chicago, IL.

Wagner, L. I., Sweet, J. J., Butt, Z., et al. (2006). Cognitive impairment associated with chemotherapy for breast cancer: an exploratory case-control study. American Society of Clinical Oncology, Clinical Science symposium: Cognitive Impairment in Cancer Survivors, Atlanta, GA.

Wechsler, J. (1997).Wechsler adult intelligence scale ( ${ }^{\text {rd }}$ ed.). San Antonio, TX: Harcourt, Brace, \& Co.

Wefel, J. S., Lenzi, R., Theriault, R. L., Davis, R. N., \& Meyers, C. A. (2004). The cognitive sequelae of standard-dose adjuvant chemotherapy in women with breast carcinoma. Cancer, 100, 2292-2299. http://dx.doi.org/10.1002/cncr.20272

Wieneke, M. H., \& Dienst, E. R. (1995). Neuropsychological assessment of cognitive functioning following chemotherapy for breast cancer. Psychooncology, 4, 61-66. http://dx.doi.org/10.1002/pon.2960040108

Table 1. Demographic and Clinical Data

\begin{tabular}{|c|c|c|}
\hline Factors & Patients $(n=23)$ & Controls $(n=23)$ \\
\hline $\operatorname{Age}^{a}$ & $51.5(8.47)$ & $50.4(8.82)$ \\
\hline Estimated IQ $^{\mathbf{a}}$ & $105.8(9.05)$ & $109.22(8.43)$ \\
\hline \multicolumn{3}{|l|}{ Education Level $^{\text {b }}$} \\
\hline High School & 2 & 3 \\
\hline College & 10 & 11 \\
\hline Bachelors & 6 & 3 \\
\hline Masters & 3 & 6 \\
\hline$P h D$ & 1 & 0 \\
\hline \multicolumn{3}{|l|}{ Marital Status $^{b}$} \\
\hline Married / Common Law & 19 & 14 \\
\hline Single & 0 & 3 \\
\hline Separated / Divorced & 2 & 6 \\
\hline Widowed & 2 & 0 \\
\hline Days since surgery $^{c}$ & $\begin{array}{l}47.6(\operatorname{Max} 71, \\
\operatorname{Min} 28)\end{array}$ & --- \\
\hline \multicolumn{3}{|l|}{ Cancer stage } \\
\hline 1 & 4 & --- \\
\hline $2 a$ & 10 & --- \\
\hline $2 b$ & 5 & $\begin{array}{ll}-- \\
---\end{array}$ \\
\hline $3 a$ & 4 & --- \\
\hline
\end{tabular}




\begin{tabular}{|c|c|c|}
\hline Menopausal status & & \\
\hline Menstruating & 8 & 9 \\
\hline Perimenopausal & 3 & 2 \\
\hline Postmenopausal & 12 & 12 \\
\hline BDI $* \mathrm{a}$ & $8.3(8.92)$ & $3.78(3.06)$ \\
\hline BAI $* \mathrm{a}$ & $7.81(7.25)$ & $4.13(4.35)$ \\
\hline $\begin{array}{l}\text { Neuropsychological Domain } \\
\text { scores }\end{array}$ & & \\
\hline 1. Verbal memory & $-0.24(1.19)$ & --- \\
\hline 2. Processing speed & $-0.11(0.91)$ & --- \\
\hline 3. Attention & $-0.26(0.86)$ & --- \\
\hline 4. Visual memory & $0.22(0.78)$ & --- \\
\hline 5. Reasoning & $-0.35(1.48)$ & --- \\
\hline 6. Verbal short-term memory & $-0.17(0.65)$ & --- \\
\hline Mean segmented brain volumes & & \\
\hline Grey matter & $\begin{array}{l}529.05 \\
(\operatorname{Max} \quad 640.09, \\
\operatorname{Min} 450.40)\end{array}$ & $\begin{array}{l}530.09 \\
(\operatorname{Max} \quad 622.41, \\
\operatorname{Min} 438.08)\end{array}$ \\
\hline White matter & $\begin{array}{l}579.92 \\
(\operatorname{Max} \quad 711.13, \\
\operatorname{Min} 454.36)\end{array}$ & $\begin{array}{l}600.51 \\
(\operatorname{Max} \quad 698.83, \\
\operatorname{Min} 521.55)\end{array}$ \\
\hline$C S F$ & $\begin{array}{l}203.31 \\
(\operatorname{Max} 257.82, \\
\operatorname{Min} 155.26)\end{array}$ & $\begin{array}{l}209.61 \\
(\operatorname{Max} 298.80, \\
\operatorname{Min} 156.18)\end{array}$ \\
\hline Total brain & $\begin{array}{l}1312.28 \\
(\operatorname{Max} 1492.54, \\
\operatorname{Min} 1123.56)\end{array}$ & $\begin{array}{l}1340.22 \\
(\operatorname{Max} 1496.24, \\
\operatorname{Min} 1120.18)\end{array}$ \\
\hline
\end{tabular}

$*$ = Significant group difference $(2$ way independent t-test, $\mathrm{p}<0.05)$.

${ }^{\mathrm{a} A g e, ~ E s t i m a t e d ~ I Q, ~ B D I, ~ B A I, ~ D o m a i n ~ s c o r e s ~=~ M e a n ~(S t D e v) . ; ~}{ }^{\mathrm{b}}$ Educational level, Marital Status, Menopausal status $=$ n.; ${ }^{\mathrm{c}}$ Days since surgery: \# of days between surgery and baseline scan.; Domain scores $=$ standardized to controls.; Abbreviations: $\mathrm{IQ}=$ Intelligence quotient, $\mathrm{BDI}=$ Beck Depression Inventory, $\mathrm{BAI}=$ Beck Anxiety Inventory. 
Table 2. Significant ${ }^{\mathrm{a}}$ regression results for grey matter in all participants, patients and controls

\section{All participants}

\begin{tabular}{|l|l|l|l|l|l|l|}
\hline Condition & Region & Atlas & $\boldsymbol{P}_{\text {FWE }}$ & $\mathbf{K}_{\mathbf{E}}$ & $\boldsymbol{T}$ value & $\begin{array}{l}\boldsymbol{Z} \\
\text { value }\end{array}$ \\
\hline $\begin{array}{l}\text { Cortisol } \\
(+)\end{array}$ & None & & & & & \\
\hline Cortisol (-) & None & & & & & \\
\hline BDI (+) & None & & & & & \\
\hline BDI (-) & L Cuneus (-12 -91 13) & aal & 0.045 & 20 & 3.44 & 3.22 \\
\hline \multirow{3}{*}{ BAI (+) } & R Parahippocampus (35 -31 27) & TD labels & 0.045 & 82 & 3.87 & 3.57 \\
\hline & R GP., lentiform nucleus (17 6 -5) & TD labels & 0.018 & 144 & 3.85 & 3.55 \\
\hline BAI (-) & None & & & & & \\
\hline $\begin{array}{l}\text { Wechsler } \\
(+)\end{array}$ & L Inferior frontal gyrus (-45 42 4) & TD labels & 0.024 & 442 & 3.83 & 3.83 \\
& L Inferior frontal gyrus (-45 30 9) & & & & 3.46 & 3.24 \\
\hline & L Middle frontal gyrus (-30 60 6) & aal & 0.016 & 583 & 4.66 & 4.18 \\
& L Middle frontal gyrus (-42 47 7) & & & 3.68 & 3.68 & 3.42 \\
\hline & L Superior frontal gyrus (-17 59 33) & aal & 0.034 & 300 & 4.17 & 3.81 \\
\hline & L Middle occipital gyrus (-14 -94 12) & TD labels & 0.038 & 152 & 4.01 & 3.68 \\
& L Middle occipital gyrus (-18 -102 3) & & 0.047 & 101 & 3.60 & 3.35 \\
\hline & L Cerebellar tonsil (-26 -36 -48) & TD labels & 0.012 & 378 & 4.58 & 4.12 \\
& L Cerebellar tonsil (-33 -63 -48) & & 0.040 & 53 & 3.61 & 3.36 \\
\hline \multirow{5}{*}{$\begin{array}{l}\text { Wechsler } \\
(-)\end{array}$} & None & & & & & \\
\hline
\end{tabular}

Patients only

\begin{tabular}{|c|c|c|c|c|c|c|}
\hline Condition & Region & Atlas & $P_{\text {FWE }}$ & $\mathbf{K}_{\mathbf{E}}$ & $T$ value & $\begin{array}{l}Z \\
\text { value }\end{array}$ \\
\hline \multirow{2}{*}{$\begin{array}{l}\text { Days since } \\
\text { surgery }(+)\end{array}$} & L Thalamus $(-8-4-2)$ & aal & 0.022 & 57 & 5.86 & 4.46 \\
\hline & R Thalamus $(6-6-3)$ & aal & 0.025 & 37 & 4.74 & 3.87 \\
\hline $\begin{array}{l}\text { Days since } \\
\text { surgery } \\
(-)\end{array}$ & L Cuneus (-18 -88 16) & TD labels & 0.031 & 186 & 5.68 & 4.37 \\
\hline $\begin{array}{l}\text { Cortisol } \\
(+)\end{array}$ & None & & & & & \\
\hline Cortisol (-) & None & & & & & \\
\hline BDI (+) & None & & & & & \\
\hline \multirow[t]{2}{*}{ BDI (-) } & R Inferior occipital gyrus (50 -76 -3) & aal & 0.045 & 68 & 4.40 & 3.66 \\
\hline & R Middle occipital gyrus (50 -76 -3) & aal & 0.021 & 97 & 4.73 & 3.86 \\
\hline BAI (+) & R GP, lentiform nucleus (15 5 -6) & TD labels & 0.031 & 35 & 3.90 & 3.34 \\
\hline BAI (-) & L Precuneus (-3 -72 40) & aal & 0.064 & 81 & 4.04 & 3.44 \\
\hline \multirow{4}{*}{$\begin{array}{l}\text { Wechsler } \\
(+)\end{array}$} & R Inferior obito-frontal gyrus (42 $45-3$ ) & aal & 0.045 & 35 & 3.93 & 3.36 \\
\hline & L Inferior frontal tri gyrus (-45 18 27) & aal & 0.044 & 63 & 3.83 & 3.30 \\
\hline & L Supramarginalgyrus (-53 -43 33) & aal & 0.010 & 320 & 4.16 & 3.88 \\
\hline & R Inferior Parietal lobule (47 -24 28) & TD labels & 0.074 & 21 & 4.31 & 3.61 \\
\hline
\end{tabular}




\begin{tabular}{|l|l|l|l|l|l|l|}
\hline & $\begin{array}{l}\text { L Posterior cerebellar declive (-36 -55 } \\
-23)\end{array}$ & TD labels & 0.009 & 501 & 4.19 & 3.54 \\
& L Posterior cerebellar declive (-42 -70 & & & & 4.13 & 3.49 \\
$-26)$ & & & & & \\
\cline { 2 - 7 } & L Posterior cerebellar tonsil (-24 -39 & TD labels & 0.047 & 37 & 3.68 & 3.20 \\
& $-45)$ & & 0.051 & 25 & 3.67 & 3.19 \\
& L Posterior cerebellar tonsil (-36 -61 & & & & & \\
\hline-47$)$ & None & & & & \\
\hline $\begin{array}{l}\text { Wechsler } \\
(-)\end{array}$ & & & & & \\
\hline
\end{tabular}

\section{Controls Only}

\begin{tabular}{|c|c|c|c|c|c|c|}
\hline Condition & Region & Atlas & $P_{\text {FWE }}$ & $\mathbf{K}_{\mathbf{E}}$ & $T$ value & $\begin{array}{l}Z \\
\text { value }\end{array}$ \\
\hline $\begin{array}{l}\text { Cortisol } \\
(+)\end{array}$ & None & & & & & \\
\hline Cortisol (-) & None & & & & & \\
\hline \multirow[t]{3}{*}{ BDI (+) } & $\begin{array}{l}\text { R Middle orbito frontal gyrus (26 } 53 \\
-12 \text { ) }\end{array}$ & aal & 0.030 & 45 & 3.84 & 3.30 \\
\hline & $\begin{array}{l}\text { Left Inferior parietal lobule }(-50-43 \\
54)\end{array}$ & aal & 0.024 & 227 & 4.57 & 3.76 \\
\hline & L Inferior temporal gyrus $(-39-37-17)$ & aal & 0.042 & 152 & 4.43 & 3.08 \\
\hline BDI (-) & None & & & & & \\
\hline \multirow[t]{2}{*}{ BAI (+) } & L Middle frontal gyrus (-33 2134$)$ & aal & 0.049 & 194 & 4.52 & 3.73 \\
\hline & R Hippocampus (21 -30 -8) & aal & 0.028 & 73 & 4.49 & 3.72 \\
\hline BAI (-) & None & & & & & \\
\hline \multirow[t]{4}{*}{$\begin{array}{l}\text { Wechsler } \\
(+)\end{array}$} & $\begin{array}{l}\text { L Superior frontal gyrus (-27 } 60 \text { 9) } \\
\text { L Superior frontal gyrus (-15 } 60 \text { 19) } \\
\text { L Superior frontal gyrus (-15 } 5933 \text { ) } \\
\text { L Superior frontal gyrus (-24 } 38 \text { 36) }\end{array}$ & aal & 0.002 & 1313 & $\begin{array}{l}6.09 \\
5.27 \\
4.10 \\
4.74\end{array}$ & $\begin{array}{l}4.57 \\
4.16 \\
3.48 \\
3.86\end{array}$ \\
\hline & L Putamen (-23 -91 16) & aal & 0.009 & 309 & 4.54 & 3.75 \\
\hline & $\begin{array}{l}\text { L Cuneus }(-12-88 \text { 15) } \\
\text { L Cuneus }(-8-10310) \\
\text { L Cuneus }(-20-1056)\end{array}$ & TD labels & 0.006 & 697 & $\begin{array}{l}4.67 \\
3.64 \\
3.66\end{array}$ & $\begin{array}{l}3.82 \\
3.64 \\
3.19\end{array}$ \\
\hline & R Superior occipital gyrus (23 -91 16) & aal & 0.022 & 179 & 4.51 & 3.73 \\
\hline $\begin{array}{l}\text { Wechsler } \\
(-)\end{array}$ & None & & & & & \\
\hline
\end{tabular}

${ }^{\mathrm{a}}$ Tables show ROI investigation at threshold 0.001 uncorrected, $\mathrm{P}_{\mathrm{FWE}}=0.05$ cluster-wise correction and $\mathrm{k}>10$. $\mathrm{N}=23$ patients, 23 controls, except cortisol with 12 patients and 15 controls. $(\mathrm{R}=$ right, $\mathrm{L}=$ left; $(+)=$ positive, $(-)$ negative). 
Table 3. Significant ${ }^{\mathrm{a}} \mathrm{t}$-test results comparing patients and controls for white matter

\section{Patients-Controls}

\begin{tabular}{|l|l|l|l|l|l|l|}
\hline Condition & Region and coordinate & Atlas & $\boldsymbol{P}_{\mathbf{F W E}}$ & $\mathbf{K}_{\mathbf{E}}$ & $\boldsymbol{t}$ value & $\boldsymbol{z}$ value \\
\hline No covariate & None & & & & & \\
\hline Cortisol & None & & & & & \\
\hline $\begin{array}{l}\text { Days since } \\
\text { surgery }\end{array}$ & L Middle occipital gyrus (-27-82 & aal & 0.069 & 17 & 3.53 & 3.29 \\
& R Parahippocampus (21-13-27) & aal & 0.037 & 11 & 3.38 & 3.16 \\
\hline BDI & R Parahippocampus (23 -12 -32) & aal & 0.029 & 64 & 3.81 & 3.52 \\
\hline BAI & R Parahippocampus (23 -12 -33) & aal & 0.038 & 10 & 3.36 & 3.15 \\
\hline Wechsler & None & & & & & \\
\hline
\end{tabular}

Controls - Patients

\begin{tabular}{|c|c|c|c|c|c|c|}
\hline Condition & Region & Atlas & $\boldsymbol{P}_{\text {FWE }}$ & $\mathbf{K}_{\mathbf{E}}$ & $t$ value & $z$ value \\
\hline \multirow{12}{*}{$\begin{array}{l}\text { No } \\
\text { covariate }\end{array}$} & L Precentralgyrus $\quad(-57-1533)$ & TD label & 0.042 & 117 & 3.83 & 3.54 \\
\hline & L Postcentralgyrus (-57 -15 33) & aal & 0.026 & 374 & 4.27 & 3.88 \\
\hline & L Precuneus (-26 -66 40) & TD label & 0.048 & 100 & 4.05 & 3.71 \\
\hline & $\begin{array}{l}\text { R Inferior Frontal Operculum (39 } 8 \\
\text { 22) }\end{array}$ & aal & 0.031 & 54 & 4.02 & 3.69 \\
\hline & $\left.\begin{array}{llll}\text { L Insula } & (-35 & 11 & 9\end{array}\right)$ & TD label & 0.010 & 661 & 3.90 & 3.60 \\
\hline & $\begin{array}{l}\text { L Inferior Frontal Operculum (-41 } 12 \\
\text { 12) }\end{array}$ & aal & 0.010 & 432 & 3.87 & 3.57 \\
\hline & L Putamen (-21 184$)$ & aal & 0.025 & 35 & 3.37 & 3.16 \\
\hline & R Supramarginal (62 -28 25) & aal & 0.034 & 77 & 3.68 & 3.42 \\
\hline & R Middle temporal gyrus (33-66 28) & TD label & 0.087 & 46 & 3.57 & 3.33 \\
\hline & L Corpus Collosum (-3 $20-0)$ & TD Br. & 0.043 & 20 & 3.46 & 3.24 \\
\hline & L Inferior Parietal lobule (-45 -49 49) & aal & 0.046 & 37 & 3,43 & 3.21 \\
\hline & L Caudate (-11 5 18) & aal & 0.043 & 20 & 3.38 & 3.17 \\
\hline \multirow[t]{7}{*}{$\begin{array}{l}\text { Diurnal } \\
\text { cortisol }\end{array}$} & $\begin{array}{l}\text { L Middle temporal gyrus (-54 }-67 \\
\text { 15) }\end{array}$ & aal & 0.036 & 282 & 4.86 & 4.01 \\
\hline & L Precentralgyrus(-57 -12 33) & TD labels & 0.042 & 228 & 4.40 & 3.73 \\
\hline & L Postcentralgyrus (-57 -12 33) & aal & 0.028 & 333 & 4.40 & 3.73 \\
\hline & R Superior frontal gyrus (17 66 7) & aal & 0.060 & 137 & 4.08 & 3.51 \\
\hline & R Superior frontal gyrus $\quad(2462$ 1) & & & & 3.90 & 3.40 \\
\hline & $\begin{array}{l}\text { R Inferior Parietal, Angular (44 -66 } \\
\text { 37) }\end{array}$ & aal & 0.042 & 29 & 3.67 & 3.24 \\
\hline & R Middle occipital gyrus (32 -67 33) & aal & 0.049 & 33 & 3.61 & 3.20 \\
\hline \multirow{2}{*}{$\begin{array}{l}\text { Days since } \\
\text { surgery }\end{array}$} & L Superior temporal pole (-39 6 -17) & aal & 0.034 & 21 & 3.57 & 3.32 \\
\hline & L Insula (-29 17 1) & aal & 0.045 & 27 & 3.52 & 3.28 \\
\hline BDI & $\begin{array}{l}\text { L Inferior Parietal lobule }(-54-57 \\
\text { 40) } \\
\text { L Parietal lobule, Angular ( }-54-57 \\
\text { 40) }\end{array}$ & $\begin{array}{l}\text { aal } \\
\text { aal }\end{array}$ & $\begin{array}{l}0.017 \\
0.020\end{array}$ & $\begin{array}{l}397 \\
106\end{array}$ & $\begin{array}{l}4.07 \\
4.02\end{array}$ & $\begin{array}{l}3.72 \\
3.69\end{array}$ \\
\hline
\end{tabular}




\begin{tabular}{|c|c|c|c|c|c|c|}
\hline & $\begin{array}{l}\text { L Precentralgyrus }(-57-1533) \\
\text { L Postcentralgyrus }(-57-1533)\end{array}$ & $\begin{array}{l}\text { TD label } \\
\text { aal }\end{array}$ & $\begin{array}{l}0.050 \\
0.038\end{array}$ & $\begin{array}{l}163 \\
217\end{array}$ & $\begin{array}{l}3.92 \\
3.92\end{array}$ & $\begin{array}{l}3.60 \\
3.60\end{array}$ \\
\hline & L Precuneus (-26 -66 39) & TD label & 0.058 & 51 & 3.70 & 3.43 \\
\hline & R Supramarginalgyrus (62-49 25) & aal & 0.034 & 78 & 3.66 & 3.40 \\
\hline & $\begin{array}{l}\text { L Inferior frontal operculum (-44 } \\
14 \text { 13) }\end{array}$ & aal & 0.027 & 49 & 3.39 & 3.17 \\
\hline \multirow[t]{7}{*}{ BAI } & L Inferior parietal lobule (-45 -49 49) & aal & 0.009 & 729 & 4.35 & 3.94 \\
\hline & L Inferior parietal lobule (-53 -60 42) & & & & 4.25 & 3.86 \\
\hline & L Precentralgyrus (-56 -15 33) & TD label & 0.053 & 72 & 3.92 & 3.52 \\
\hline & L Postcentralgyrus $\quad(-56-1533)$ & aal & 0.035 & 61 & 3.81 & 3.61 \\
\hline & L Insula (-35 9 9) & aal & 0.022 & 246 & 3.56 & 3.32 \\
\hline & $\begin{array}{l}\text { R Inferior frontal operculum (398 } 8 \\
\text { 22) }\end{array}$ & aal & 0.039 & 10 & 3.50 & 3.27 \\
\hline & R Supramarginalgyrus(63-46 25) & aal & 0.046 & 13 & 3.45 & 3.22 \\
\hline \multirow[t]{7}{*}{ Wechsler } & L Precentralgyrus $\quad(-56-1531)$ & TD label & 0.043 & 218 & 4.30 & 3.90 \\
\hline & 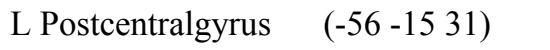 & aal & 0.026 & 383 & 4.30 & 3.90 \\
\hline & L Insula (-42 12 12) & TD label & 0.014 & 492 & 3.86 & 3.55 \\
\hline & $\begin{array}{l}\text { L Inferior frontal operculum }(-42 \\
12 \text { 12) }\end{array}$ & aal & 0.012 & 346 & 3.86 & 3.55 \\
\hline & L Precuneus (-26 -66 40) & TD label & 0.053 & 72 & 3.82 & 3.52 \\
\hline & $\begin{array}{l}\text { L Middle occipital gyrus (-26 }-66 \\
\text { 40) }\end{array}$ & aal & 0.060 & 49 & 3.82 & 3.52 \\
\hline & $\begin{array}{l}\text { R Inferior frontal operculum (39 } 8 \\
\text { 22) }\end{array}$ & aal & 0.037 & 19 & 3.66 & 3.40 \\
\hline
\end{tabular}

${ }^{a}$ Tables show significant ROI investigation at threshold 0.001 uncorrected, $\mathrm{P}_{\mathrm{FWE}}=0.05$ cluster-wise correction and $\mathrm{k}>10 . . \mathrm{N}=23$ patients and 23 controls, except cortisol with 12 patients and 15 controls. $(\mathrm{R}=$ right, $\mathrm{L}=$ left).

Table 4. Significant ${ }^{\mathrm{a}}$ regression results for white matter in all participants, patients and controls

\section{All participants}

\begin{tabular}{|l|l|l|l|l|l|l|}
\hline Condition & Region & Atlas & $P_{\mathrm{FWE}}$ & $\mathrm{K}_{\mathrm{E}}$ & $T$ value & $Z$ value \\
\hline & & & & & & \\
\hline $\begin{array}{l}\text { Cortisol } \\
(+)\end{array}$ & L Precuneus (-5 -63 52) & TD labels & 0.055 & 84 & 3.95 & 3.45 \\
\cline { 2 - 8 } & L Superior occipital gyrus (-18 -91 31) & TD labels & 0.052 & 46 & 3.93 & 3.43 \\
\hline Cortisol (-) & None & & & & & \\
\hline \multirow{3}{*}{ BDI (+) } & L Inferior temporal gyrus (-57 -24 -26) & aal & 0.028 & 286 & 3.92 & 3.61 \\
& L Superior temporal pole (-50 8 -12 & aal & 0.025 & 100 & 3.92 & 3.61 \\
\hline \multirow{3}{*}{ BDI (-) } & R Inferior frontal operculum (39 6 24) & aal & 0.020 & 187 & 4.58 & 4.12 \\
\cline { 2 - 7 } & L medial frontal gyrus (-12 45 15) & TD labels & 0.010 & 1085 & 4.11 & 4.11 \\
& L medial frontal gyrus (-6 59 21) & & & & 3.82 & 3.82 \\
\cline { 2 - 8 } & Right Superior frontal gyrus (15 66 10) & TD labels & 0.042 & 356 & 4.65 & 4.17 \\
& Right Superior frontal gyrus (23 51 3) & & & & 3.89 & 3.59 \\
& Right Superior frontal gyrus (6 62 3) & & & & 3.62 & 3.37 \\
\hline
\end{tabular}




\begin{tabular}{|c|c|c|c|c|c|c|}
\hline & $\begin{array}{l}\text { R Anterior cingulate (9 } 36 \text { 16) } \\
\text { R Anterior cingulate (12 } 443 \text { 3) }\end{array}$ & aal & 0.012 & 356 & $\begin{array}{l}3.83 \\
3.74\end{array}$ & $\begin{array}{l}3.54 \\
3.47\end{array}$ \\
\hline & $\begin{array}{l}\text { L Anterior cingulate }\left(\begin{array}{lll}-6 & 18 & 30\end{array}\right) \\
\text { L Anterior cingulate }\left(\begin{array}{lll}-8 & 27 & 25\end{array}\right)\end{array}$ & aal & 0.020 & 209 & $\begin{array}{l}4.57 \\
3.88\end{array}$ & $\begin{array}{l}4.11 \\
3.58\end{array}$ \\
\hline & L Insula (-38 -22 16) & TD labels & 0.038 & 80 & 3.58 & 3,34 \\
\hline & R Caudate (18 23 10) & aal & 0.025 & 48 & 3.41 & 3.20 \\
\hline & L Superior parietal lobule (-17 -54 61) & TD labels & 0.026 & 30 & 3.62 & 3.32 \\
\hline & L Precuneus (-24 -58 52) & TD labels & 0.044 & 133 & 3.92 & 3.61 \\
\hline & 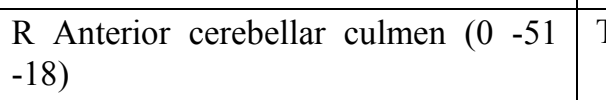 & TD labels & 0.052 & 34 & 3.43 & 3.21 \\
\hline & $\begin{array}{l}\begin{array}{l}\text { L Posterior cerebellar declive (3.-63 } \\
-18)\end{array}\end{array}$ & TD labels & 0.034 & 72 & 3.47 & 3.25 \\
\hline & $\begin{array}{l}\text { L Posterior cerebellar tonsil }\left(\begin{array}{ll|l}-23 & -48 \\
-47\end{array}\right)\end{array}$ & TD labels & 0.037 & 31 & 3.40 & 3.18 \\
\hline BAI (+) & L Angular gyrus (-42 -60 39) & aal & 0.027 & 35 & 3.46 & 3.23 \\
\hline BAI (-) & L Inferior orbito-frontal (-48 36 -6) & aal & 0.025 & 117 & 3.74 & 3.47 \\
\hline \multirow{4}{*}{$\begin{array}{l}\text { Wechsler } \\
(+)\end{array}$} & R Precentralgyrus (50 -15 59) & aal & 0.033 & 246 & 4.32 & 3.92 \\
\hline & R Postcentralgyrus (54 -25 51) & aal & 0.021 & 508 & 3.97 & 3.65 \\
\hline & R Precuneus (21 -57 48) & aal & 0.045 & 130 & 3.75 & 3.48 \\
\hline & L Cuneus (-5 -73 4) & TD labels & 0.024 & 281 & 4.31 & 3.91 \\
\hline Wechsler (-) & None & & & & & \\
\hline \multicolumn{7}{|l|}{ tients only } \\
\hline Condition & Region & Atlas & $P_{\mathrm{FWE}}$ & $\mathrm{K}_{\mathrm{E}}$ & $T$ value & $Z$ value \\
\hline \multirow[t]{2}{*}{$\begin{array}{l}\text { Days since } \\
\text { surgery }(+)\end{array}$} & $\begin{array}{l}\text { L Insula }(-3211-18) \\
\text { L Insula }(-395-14)\end{array}$ & aal & 0.029 & 156 & $\begin{array}{l}4.24 \\
3.97\end{array}$ & $\begin{array}{l}3.57 \\
3.39\end{array}$ \\
\hline & L Putamen (-29 $12-0)$ & aal & 0.028 & 19 & 3.68 & 3.20 \\
\hline $\begin{array}{l}\text { Days since } \\
\text { surgery }(-)\end{array}$ & R Inferior frontal triangularis (56 20 4) & aal & 0.042 & 34 & 3.89 & 3.34 \\
\hline \multirow[t]{5}{*}{$\begin{array}{l}\text { Cortisol } \\
(+)\end{array}$} & $\begin{array}{l}\text { R Middle frontal gyrus (33 } 39-11 \text { ) } \\
\text { R Middle frontal gyrus (27 } 42 \text {-17) } \\
\text { R Middle frontal gyrus (32 } 50 \text {-5) } \\
\text { R Middle frontal gyrus (36 } 35-5 \text { ) }\end{array}$ & $\begin{array}{l}\text { TD } \\
\text { labels }\end{array}$ & 0.009 & 791 & $\begin{array}{l}5.98 \\
5.78 \\
5.45 \\
5.07\end{array}$ & $\begin{array}{l}3.81 \\
3.75 \\
3.63 \\
3.49\end{array}$ \\
\hline & R Superior orbito-frontal (11 45 -23) & aal & 0.029 & 90 & 5.26 & 3.56 \\
\hline & $\begin{array}{l}\text { R Cingulate gyrus }(9-2833) \\
\text { R Cingulate gyrus }(2-2431)\end{array}$ & $\begin{array}{l}\text { TD } \\
\text { labels }\end{array}$ & 0.025 & 250 & $\begin{array}{l}5.57 \\
5.31\end{array}$ & $\begin{array}{l}3.68 \\
3.58\end{array}$ \\
\hline & L Rolandic Operculum (-47 -4 16) & aal & 0.020 & 141 & 5.27 & 3.57 \\
\hline & $\begin{array}{l}\text { L Anterior cerebellar culmen }\left(\begin{array}{ll}-36 & -45 \\
-36\end{array}\right) \\
\text { L Anterior cerebellar culmen }(-33-54 \\
-32)\end{array}$ & $\begin{array}{l}\text { TD } \\
\text { labels }\end{array}$ & 0.033 & 171 & $\begin{array}{l}4.96 \\
4.94\end{array}$ & $\begin{array}{l}3.44 \\
3.44\end{array}$ \\
\hline Cortisol (-) & None & & & & & \\
\hline BDI $(+)$ & None & & & & & \\
\hline
\end{tabular}




\begin{tabular}{|l|l|l|l|l|l|l|}
\hline \multirow{2}{*}{ BDI (-) } & R Inferior frontal triangularis (39 35 6) & aal & 0.031 & 110 & 4.23 & 3.56 \\
\cline { 2 - 7 } & $\begin{array}{l}\text { R Brainstem (2 -19 -20) } \\
\text { R Brainstem (12 -16 -23) }\end{array}$ & $\begin{array}{l}\text { TD } \\
\text { labels }\end{array}$ & 0.033 & 121 & 3.78 & 3.27 \\
\hline BAI (+) & L Angular gyrus (-44 -58 39) & aal & 0.027 & 46 & 3.84 & 3.30 \\
\hline BAI (-) & $\begin{array}{l}\text { L Superior medial frontal gyrus (-11 45 } \\
43)\end{array}$ & aal & 0.048 & 73 & 4.16 & 3.51 \\
\hline $\begin{array}{l}\text { Wechsler } \\
(+)\end{array}$ & None & & & & & \\
\hline \multirow{2}{*}{ Wechsler (-) } & $\begin{array}{l}\text { L Inferior orbito-frontal gyrus (-42 23 } \\
-15)\end{array}$ & aal & 0.041 & 14 & 3.64 & 3.17 \\
\cline { 2 - 7 } & R Corpus callosum (2 -30 12) & TD Br. & 0.043 & 31 & 3.68 & 3.19 \\
\cline { 2 - 7 } & L Corpus callosum (-2 -30 12) & TD Br. & 0.043 & 23 & 3.68 & 3.20 \\
\hline
\end{tabular}

\section{Controls Only}

\begin{tabular}{|c|c|c|c|c|c|c|}
\hline Condition & Region & Atlas & $P_{\mathrm{FWE}}$ & $\mathrm{K}_{\mathrm{E}}$ & $T$ value & $Z$ value \\
\hline $\begin{array}{l}\text { Cortisol } \\
(+)\end{array}$ & None & & & & & \\
\hline Cortisol (-) & R Parahippocampus (35 -27 -26) & TD labels & 0.036 & 140 & 5.49 & 3.88 \\
\hline $\mathrm{BDI}(+)$ & None & & & & & \\
\hline \multirow[t]{2}{*}{ BDI (-) } & $\begin{array}{l}\text { L Middle frontal gyrus }(-24-352) \\
\text { L Middle frontal gyrus }(-36-452)\end{array}$ & TD labels & 0.020 & 718 & $\begin{array}{l}5.00 \\
4.05\end{array}$ & $\begin{array}{l}4.01 \\
3.45\end{array}$ \\
\hline & L Precentralgyrus (-9 -28 75) & TD labels & 0.035 & 288 & 4.33 & 3.62 \\
\hline $\mathrm{BAI}(+)$ & $\begin{array}{l}\text { L Posterior cerebellar declive }\left(\begin{array}{ll}-8 & 81 \\
-21\end{array}\right)\end{array}$ & TD labels & 0.039 & 66 & 4.30 & 3.60 \\
\hline BAI (-) & None & & & & & \\
\hline \multirow[t]{4}{*}{$\begin{array}{l}\text { Wechsler } \\
(+)\end{array}$} & $\begin{array}{l}\text { R Posterior cingulate gyrus }\left(\begin{array}{lll}9 & -67 & 12\end{array}\right) \\
\text { R Posterior cingulate gyrus }\left(\begin{array}{lll}2 & -70 & 10\end{array}\right)\end{array}$ & TD labels & 0.019 & 107 & $\begin{array}{l}3.95 \\
3.58\end{array}$ & $\begin{array}{l}3.38 \\
3.12\end{array}$ \\
\hline & $\begin{array}{l}\text { R Caudate (17 } 18 \text { 10) } \\
\text { R Caudate (15 } 321 \text { 21) }\end{array}$ & aal & 0.005 & 605 & $\begin{array}{l}4.97 \\
4.18\end{array}$ & $\begin{array}{l}4.00 \\
3.53\end{array}$ \\
\hline & $\begin{array}{l}\text { R Precuneus (21 -57 51) } \\
\text { R Precuneus (6 -64 15) }\end{array}$ & aal & 0.025 & 334 & $\begin{array}{l}5.28 \\
3.88\end{array}$ & $\begin{array}{l}4.17 \\
3.33\end{array}$ \\
\hline & L Cuneus (-2 -79 21) & aal & 0.036 & 56 & 3.74 & 3.28 \\
\hline Wechsler (-) & None & & & & & \\
\hline
\end{tabular}

${ }^{a}$ Tables show significant ROI investigation at threshold 0.001 uncorrected, $\mathrm{P}_{\mathrm{FWE}}=0.05$ cluster-wise correction and $\mathrm{k}>10 . . \quad \mathrm{N}=23$ patients, 23 controls, except cortisol with 12 patients and 15 controls. $(\mathrm{R}=$ right, $\mathrm{L}=$ left; $(+)$ $=$ positive,$(-)=$ negative $)$. 


\section{Diurnal cortisol}

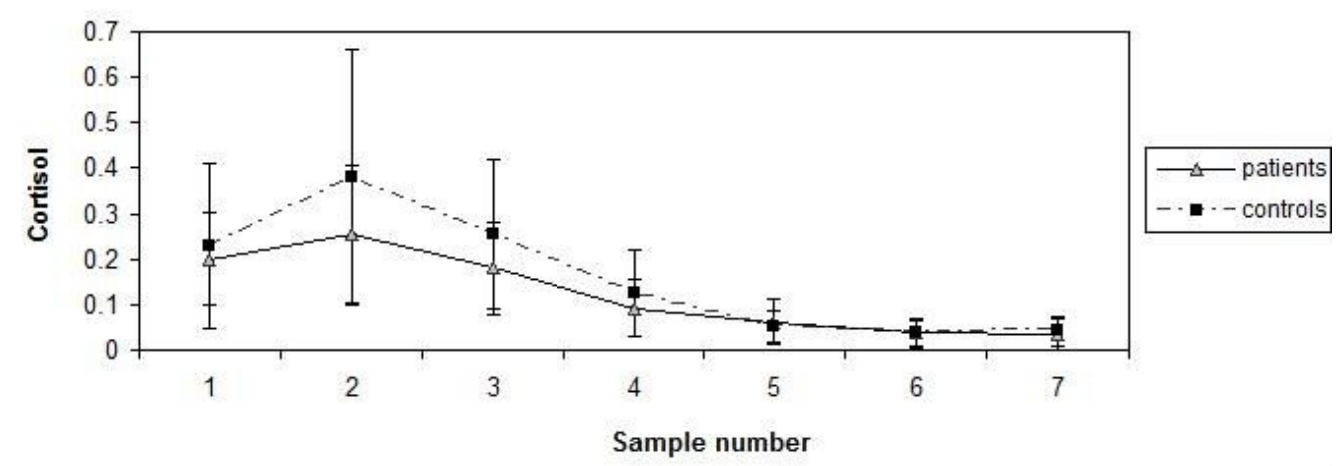

Figure 1. Diurnal cortisol rhythms for breast cancer patients and matched controls

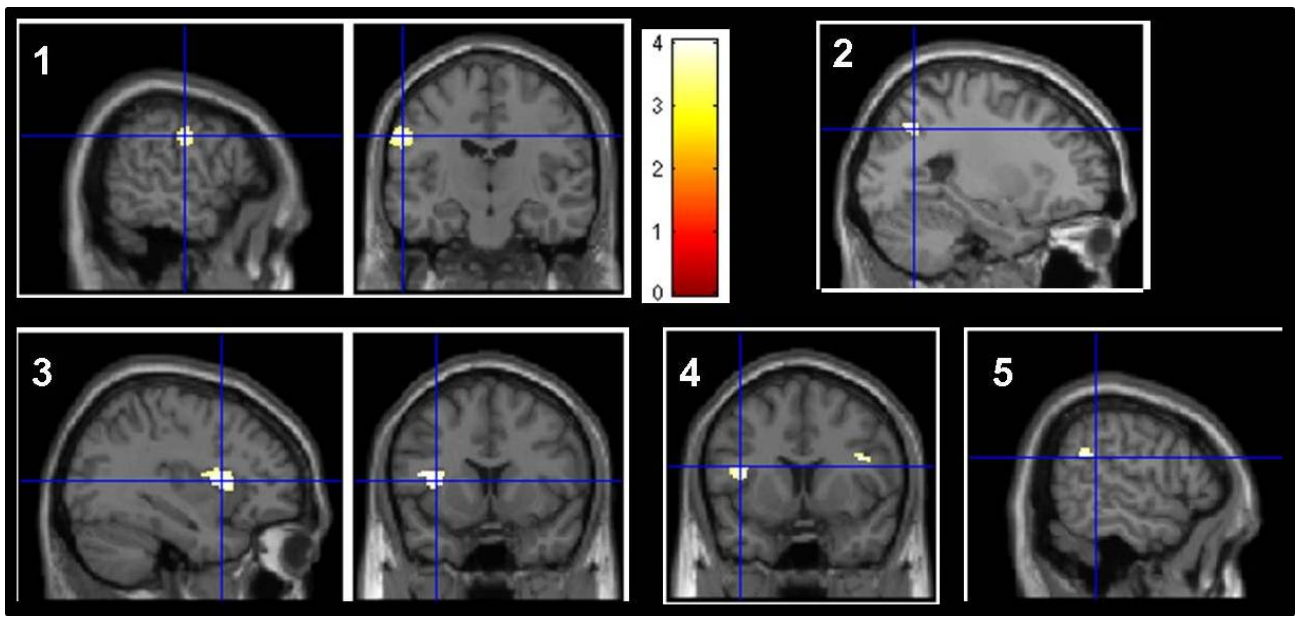

Figure 2. Significant t-test results for controls - patients for white matter

1. Left precentral and postcentralgyri

2. Left precuneus

3. Left insula

4. Bilateral inferior frontal operculum

5. Right supramarginalgyrus 